\title{
The Global-Scale Observations of the Limb and Disk (GOLD) Mission
}

\author{
R.W. Eastes ${ }^{1}$ - W.E. McClintock ${ }^{2}$ - A.G. Burns ${ }^{3}$ - D.N. Anderson ${ }^{4,5}$ - L. Andersson ${ }^{2}$. \\ M. Codrescu ${ }^{4}$ - J.T. Correira ${ }^{6}$ - R.E. Daniell ${ }^{7}$ - S.L. England ${ }^{8} \cdot$ J.S. Evans ${ }^{6} \cdot$ J. Harvey $^{9}$ \\ A. Krywonos ${ }^{1}$. J.D. Lumpe ${ }^{10}$ - A.D. Richmond ${ }^{3}$ - D.W. Rusch ${ }^{2}$ O. Siegmund ${ }^{11}$. \\ S.C. Solomon ${ }^{3}$ - D.J. Strickland ${ }^{6}$ - T.N. Woods ${ }^{2} \cdot$ A. Aksnes ${ }^{12}$ - S.A. Budzien ${ }^{13}$. \\ K.F. Dymond ${ }^{13}$ - F.G. Eparvier ${ }^{2}$ C.R. Martinis $^{14}$ • J. Oberheide ${ }^{15}$
}

Received: 19 April 2017 / Accepted: 20 June 2017 / Published online: 7 August 2017

(C) The Author(s) 2017. This article is published with open access at Springerlink.com

\begin{abstract}
The Earth's thermosphere and ionosphere constitute a dynamic system that varies daily in response to energy inputs from above and from below. This system can exhibit a significant response within an hour to changes in those inputs, as plasma and fluid processes compete to control its temperature, composition, and structure. Within this system, short wavelength solar radiation and charged particles from the magnetosphere deposit energy, and waves propagating from the lower atmosphere dissipate. Understanding the global-scale response of the thermosphere-ionosphere (T-I) system to these drivers is essential to advanc-
\end{abstract}

\author{
R.W. Eastes \\ richard.eastes@ucf.edu \\ W.E. McClintock \\ bill.mcclintock@1asp.colorado.edu \\ A.G. Burns \\ aburns@ucar.edu \\ D.N. Anderson \\ david.anderson@noaa.gov \\ L. Andersson \\ laila.andersson@1asp.colorado.edu \\ M. Codrescu \\ mihail.codrescu@noaa.gov \\ J.T. Correira \\ correira@cpi.com \\ R.E. Daniell \\ daniell@ionosphericphysics.com \\ S.L. England \\ englands@vt.edu \\ J.S. Evans \\ evans@cpi.com \\ J. Harvey \\ jimh@photonengr.com
}

A. Krywonos

krywonos@ucf.edu 
ing our physical understanding of coupling between the space environment and the Earth's atmosphere. Previous missions have successfully determined how the "climate" of the T-I system responds. The Global-scale Observations of the Limb and Disk (GOLD) mission will determine how the "weather" of the T-I responds, taking the next step in understanding the coupling between the space environment and the Earth's atmosphere. Operating in geostationary orbit, the GOLD imaging spectrograph will measure the Earth's emissions from 132 to $162 \mathrm{~nm}$. These measurements will be used image two critical variables-thermospheric temperature and composition, near $160 \mathrm{~km}$ - on the dayside disk at half-hour time scales. At night they will be used to image the evolution of the low latitude ionosphere in the same regions that were observed earlier during the day. Due to the geostationary orbit being used the mission observes the same hemisphere repeatedly, allowing the unambiguous separation of spatial and temporal variability over the Americas.

Keywords Ultraviolet · Thermosphere $\cdot$ Ionosphere $\cdot$ Imaging $\cdot$ Remote sensing $\cdot$ Satellite

\title{
1 Introduction
}

The GOLD mission is focused on four primary scientific questions regarding the response of the Earth's thermosphere and ionosphere to forcing from above and below. Understanding the response to this forcing is one of the most prominent challenges for research in the Earth's space environment. Each of the four primary questions are addressed through the examination of more focused questions that can be addressed using the high cadence,

\footnotetext{
J.D. Lumpe

lumpe@cpi.com
}

\author{
A.D. Richmond \\ richmond@ucar.edu \\ D.W. Rusch \\ david.rusch@1asp.colorado.edu \\ O. Siegmund \\ ossy@ssl.berkeley.edu \\ S.C. Solomon \\ stans@ucar.edu \\ D.J. Strickland \\ dstrick@cpi.com \\ T.N. Woods \\ tom.woods@lasp.colorado.edu
}

\section{A. Aksnes}

Arve.Aksnes@mnfa.uib.no

\section{S.A. Budzien}

scott.budzien@nrl.navy.mil

K.F. Dymond

kenneth.dymond@nrl.navy.mil

F.G. Eparvier

eparvier@lasp.colorado.edu

C.R. Martinis

martinis@bu.edu 


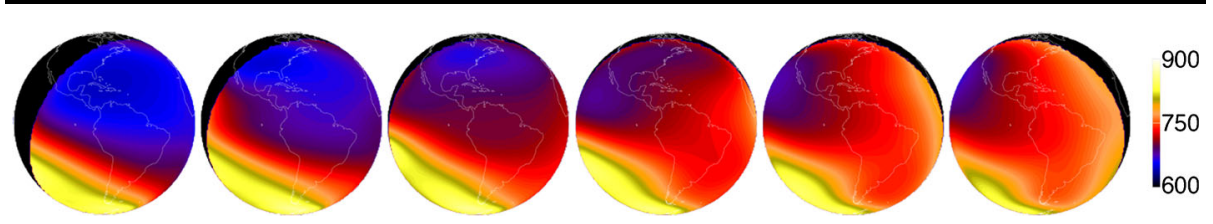

Fig. 1 Modeled thermospheric temperature $(\mathrm{K})$ progression at one-hour intervals, during a geomagnetic storm, near $160 \mathrm{~km}$ altitude, as sampled by GOLD from geostationary orbit

global-scale images observed by a ultraviolet (UV) imager in geostationary orbit. This orbit allows the GOLD imager to make repeated images, covering most of the hemisphere over the Americas, of the same geographic locations throughout a day, as portrayed in Fig. 1. Previous missions, e.g. TIMED, have demonstrated the value of imaging the thermospheric composition $\left(\mathrm{O} / \mathrm{N}_{2}\right.$ density ratio) on the dayside, and peak ionospheric densities on the nightside. Such imaging has led to major advances in understanding the behavior of the T-I system. GOLD will make similar measurements of the $\mathrm{O} / \mathrm{N}_{2}$ density ratio, adding simultaneous measurements of the thermospheric temperatures at the same altitudes, and the observations will cover the American hemisphere for most of each day and at a high cadence.

The first of the four primary science questions, "How do geomagnetic storms alter the temperature and composition structure of the thermosphere?", is directed at understanding the most variable of the two major sources of forcing from above. The second primary science question, "What is the global-scale response of the thermosphere to solar extremeultraviolet variability?", is directed at understanding the influence of what is typically the

\section{J. Oberheide}

joberhe@clemson.edu

1 Florida Space Institute, University of Central Florida, 12354 Research Parkway, Orlando, FL 32826-0650, USA

2 Laboratory for Atmospheric and Space Physics, University of Colorado, Boulder, CO 80303-7814, USA

3 NCAR, PO Box 3000, Boulder, CO 80307-3000, USA

4 NOAA-SEC, 325 Broadway, Boulder, CO 80305-3337, USA

5 Cooperative Institute for Research in Environmental Sciences, University of Colorado, 216 UCB, Boulder, CO 80309, USA

6 Computational Physics, 8001 Braddock Road, Springfield, VA 22151-2110, USA

7 Ionospheric Physics, 38 Sandy Ridge Road, Stoughton, MA 02072-2226, USA

8 Aerospace \& Ocean Engineering, Virginia Tech, 1901 Innovation Dr., Blacksburg, VA 24061, USA

9 Photon Engineering, 440 S Williams Blvd., Tucson, AZ 85711-4403, USA

10 Computational Physics, Inc., 1650 38th Street, Boulder, CO 80301-2623, USA

11 Space Science Lab., Univ. of California, Berkeley, CA 94720-5071, USA

12 University of Bergen, Nygårdshøyden, 5020 Bergen, Norway

13 Naval Research Laboratory, 4555 Overlook Ave., SW Washington, DC 20375-0001, USA

14 Center for Space Physics, Boston University, Boston, MA 02215-1401, USA

15

Physics Department, Clemson University, Clemson, SC 29634-0978, USA 
primary source of forcing from above, the extreme-ultraviolet (EUV) and soft X-ray (XUV) spectral range from $\sim 1 \mathrm{~nm}$ to $\sim 103 \mathrm{~nm}$. This is the most important solar spectral region for T-I variability and the entire spectral region will be referred to as the EUV in this paper. The third primary science question, "How significant are the effects of atmospheric waves and tides propagating from below on the thermospheric temperature structure?", is directed at understanding the influence of forcing that may come from the lower atmosphere (e.g., gravity waves) or be generated within the T-I system as a result of the forcing. While this source of forcing to the T-I system is expected to be less than solar and geomagnetic forcing (the two primary sources) at most locations, it now appears to be a significant contributor to the day-to-day differences between observations and models. The fourth of the primary science question, "How does the structure of the equatorial ionosphere influence the formation and evolution of equatorial plasma density irregularities?", is directed at understanding how the low latitude, nighttime ionosphere responds to the preconditioning that occurs on the dayside and to geomagnetic activity.

Although there are extensive measurements of the T-I system by instruments on lowEarth-orbiting (LEO) spacecraft and on the ground, we lack the data necessary to sufficiently answer the four questions summarized above. High-cadence, global-scale measurements of both the composition and temperatures in the lower thermosphere can provide the necessary perspective and insights into the variability and interactions. LEO spacecraft can only sample a narrow swath of the T-I system during each orbit. Since it takes 12 hours or more to obtain a global picture using LEO data, such observations do not allow definitive separation of spatial and temporal variations for dynamic events, which play an important role in the behavior of the T-I system. Imagers located in highly elliptical orbits have broader spatial coverage, but they observe varying geographic regions, limiting the insights that can be obtained. Due to these inherent limitations, previous missions have been unable to provide the continuous, high cadence, simultaneous observations of temperature and composition needed to relate complex plasma-neutral interactions to the state of the T-I system.

Thermospheric composition has been extensively studied by remote sensing, primarily through measurements of the ratio of atomic oxygen to molecular nitrogen or simply $\mathrm{O} / \mathrm{N}_{2}$ as well as by in-situ methods. Insights into the T-I response to geomagnetic storms have come from such measurements (e.g., Prölss 2011), and simultaneous temperature observations can leverage them to provide further insights. Temperature changes directly affect the density and composition of the thermosphere, and thereby the ionosphere, which is strongly coupled to the neutral atmosphere.

GOLD will make global-scale thermospheric temperature measurement using observations of the rotational structure of $\mathrm{N}_{2}$ LBH bands. Aksnes et al. (2006) have demonstrated the feasibility of this technique by comparing temperatures derived from data obtained with the High-resolution Ionospheric and Thermospheric Spectrograph (HITS) on the Advanced Research and Global Observation Satellite (ARGOS) to the Mass Spectrometer and Incoherent Scatter (MSIS) model. There is excellent agreement between their retrieved temperatures and the MSIS model, as shown in Fig. 2. Full end-to-end retrievals have also been demonstrated by running the GOLD retrieval algorithms with simulated data calculated using neutral densities from the NCAR TIE-GCM model.

Modeling of the global thermosphere and ionosphere, using general circulation models such as the NCAR TIE-GCM, is mature, and includes the physical processes that control the coupled T-I system (e.g., Burns et al. 2007). Such models agree well with empirical models of the thermosphere and with the qualitative response of the T-I system. Yet, the ability of any models to match observed events is limited by uncertainty in the drivers from above and below (e.g., Fuller-Rowell et al. 2006). Comprehensive observations of T-I state parameters 
Fig. 2 Comparison of temperatures measured by ARGOS HITS to the MSIS model (dashes)

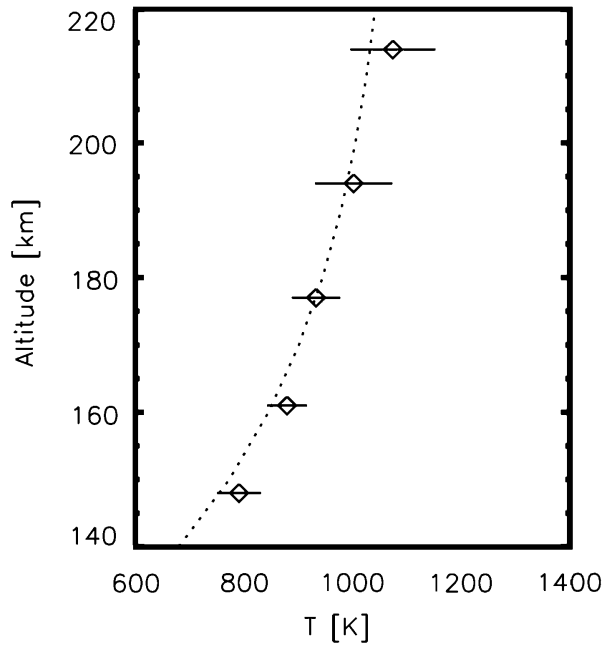

such as composition and temperature are therefore a key to reducing the uncertainties and advancing these models from climatological descriptions to realistic space weather simulations. The continuous, high-cadence, global-scale observations from the GOLD mission will resolve the temporal and spatial response to solar and geomagnetic inputs, which is not possible with current or historical data.

This paper will discuss the scientific background to these questions and the mission architecture. Additional details regarding the state of our knowledge about these questions and the measurements GOLD will make to address the questions as well as a full description the UV imager will be covered in forthcoming papers by S.C. Solomon and by W.E. McClintock respectively. An extensive review of previous UV observations is covered in a forthcoming review by A.G. Burns, the GOLD mission project scientist.

\section{Science Objectives}

While the four primary science questions to be addressed by the GOLD mission are broad and UV remote sensing is only one of the measurement techniques that have been used in previous efforts to address them, the imaging capabilities of the GOLD mission allow it to address key, more specific issues about these questions from a new perspective. The primary science question as well as the more specific issues that the mission will address and the rationale for them are described below.

Question 1 How do geomagnetic storms alter the temperature and composition structure of the thermosphere?

Geomagnetic storms drive large changes in the temperature and composition of the thermosphere. Forcing by geomagnetic storms occurs primarily in the high-latitude, auroral regions, but storm effects extend throughout the middle and low latitudes (e.g., Fig. 1). Previous studies of storms had limited ability to uniquely separate local time and longitude changes at global scales, which has made it difficult to understand the three-dimensional, time-varying response (e.g., Burns et al. 2007) of the T-I system. Observations from the 
ground and LEO satellites have not constrained the models sufficiently to substantially advance our current understanding. The ability of general circulation models and empirical models to describe storm-time changes is limited by an observational deficit, as they are currently based more on superposition of changing climatic states than on the full temporal and spatial analysis enabled by global-scale imaging.

GOLD will provide, for the first time, a large-scale depiction of storm driven changes in both temperature and neutral composition. This will enable the study of geomagnetic storm effects by examining three more specific issues:

(a) whether the initial temperature and composition distribution affect the response to storms,

(b) how the vertical structure of $\mathrm{O}_{2}$ changes during storms and

(c) whether the T-I recovery from storms is controlled by temperature or composition.

Every geomagnetic storm is unique, since the interplanetary magnetic field, solar wind, and magnetospheric drivers are diverse (Burns et al. 2014). Not only does the magnetospheric convection and auroral precipitation vary from one storm to another, but the preconditioned state of the T-I system prior to storm onset may also contribute to its progression. The factors that control this may include solar activity, the time of year, the time of onset (which determines the position of the terrestrial magnetic field and auroral oval relative to the Sun), previous geomagnetic disturbances, flares or other changes in solar EUV, and lower atmosphere influences from waves and tides. Yet, in the T-I system, there are many common features (e.g., Wang et al. 2010a, 2010b), due to the general pattern of high-latitude heating, composition change driven by vertical motions, meridional winds that carry these changes to lower latitude, and alteration of the global ionosphere electric potential.

Furthermore, since GOLD will image the same geographic locations continuously, the large-scale distribution of temperature and composition in the quiet-time thermosphere can be contrasted with the $\sim 10$ or more moderate storms that typically occur every year. Maps of the response of temperature and composition, observed on the disk, will be compared to the equivalent maps for quiet times. Changes in $\mathrm{O}_{2}$ density profiles, observed on the limb, will also be analyzed. The response of the nighttime equatorial ionosphere, which may also vary, will be quantified using nightside observations.

Quantifying the geomagnetic forcing requires the combining of high-latitude potential and conductance data from multiple sources. We will use the Assimilative Mapping of Ionospheric Electrodynamics (AMIE) procedure (Richmond and Kamide 1988) to combine these data. This method provides a comprehensive time-dependent description of magnetospheric forcing of the T-I system. AMIE can employ various data inputs, including space-based measurements; in its basic form it can be run using ground-based magnetometer data alone, which are certain to be available during the GOLD mission. AMIE runs will be used to provide high-latitude inputs to general circulation models.

To elucidate the physics underlying the T-I response to geomagnetic storms, three models will be employed to analyze GOLD observations: the Thermosphere-IonosphereElectrodynamics General Circulation model (TIE-GCM) (Richmond et al. 1992), Coupled Thermosphere Ionosphere Plasmasphere electrodynamics model (CTIPe) (Millward et al. 2001; Codrescu et al. 2008), and the semi-empirical NRLMSISE-00 model (Picone et al. 2002). Magnetospheric inputs to the T-I system will be combined with solar and tidal input parameters to drive TIE-GCM and CTIPe, in order to explore the compositional, thermal, and dynamical signatures present in GOLD images. Using different numerical models allows systemic deviations between the models to be studied and the important differences in parameterization of physical processes to be identified. 
Question 2 What is the global-scale response of the thermosphere to solar extremeultraviolet variability?

Solar radiation is the principal driver of variation in the thermospheric climate. Ultraviolet radiation and X-rays ionize the neutral gas, driving dynamics and thermodynamics and producing the low and middle latitude ionosphere. The most important spectral region for T-I variability is the extreme-ultraviolet (EUV) and soft X-ray (XUV) spectral range, from $\sim 1 \mathrm{~nm}$ to $\sim 103 \mathrm{~nm}$, which we collectively refer to as EUV. Thermospheric measurements by GOLD will enable the separation of spatial and temporal effects from this radiation, including during solar flares. The thermospheric response will be addressed by examining two more specific issues:

(a) the response of thermospheric temperature and composition to solar EUV forcing and

(b) whether the thermospheric response to flares is commensurate with measured solar emissions.

There are still significant controversies concerning the consistency of solar measurements, thermospheric measurements, and the models that combine them (e.g., Solomon et al. 2013; Sojka et al. 2014). Measurements by the TIMED satellite Solar Extreme-ultraviolet Experiment (SEE) and Global Ultraviolet Imager (GUVI) have made important advances (e.g. Strickland et al. 2004a; Woods et al. 2005, 2008; Meier et al. 2015). These issues motivated the next generation of spectrally resolved, high-cadence observations by the SDO Extremeultraviolet Variability Experiment (EVE) (Woods et al. 2009, 2012), and the NOAA GOES EUV and XRS monitors (Evans et al. 2010). Solar measurements, solar proxy indices, and solar models based on SEE and EVE data will be used for comparison with GOLD observations, in particular, the estimate of the ionizing radiation from 1 to $45 \mathrm{~nm}$, " $Q_{\text {EUV }}$ ", that will be obtained from the intensity of GOLD dayglow observations themselves, using a procedure developed using GUVI data (cf., Strickland et al. 2004b, 2007).

The solar-driven thermospheric circulation, with upwelling in the dayside and summer hemispheres and downwelling in the nightside and winter hemispheres, produces variations in $\mathrm{O} / \mathrm{N}_{2}$ (e.g., Burns et al. 2015) that will be observed by GOLD. The global effects of solar EUV variations are described by general circulation models of the coupled T-I system. These include solar forcing of the thermospheric temperature on timescales of the solar cycle, solar-rotation and solar flares. Comparisons of observations and general circulation models using measured solar EUV spectra as inputs (e.g., Solomon and Qian 2005) will elucidate whether model descriptions of thermospheric circulation and temperature variation due to solar forcing are sufficient.

Solar EUV radiation not only drives changes in $\mathrm{O} / \mathrm{N}_{2}$, it also causes variations in $\mathrm{O}_{2}$, which GOLD also can measure. Solar occultation measurements from Solar Maximum Mission (SMM; Aikin et al. 1993) and Solar Ultraviolet Spectral Irradiance Monitor (SUSIM; Lumpe et al. 2007), incorporated into NRLMSISE-00, imply a 30\% decrease in $\mathrm{O}_{2}$ at 200 $\mathrm{km}$ from solar minimum to maximum, in approximate agreement with numerical models that include $\mathrm{O}_{2}$ dissociative chemistry, but at variance with earlier empirical models that predicted a factor of two increase from minimum to maximum. GOLD stellar occultation measurements will provide $\mathrm{O}_{2}$ densities over a wide range of latitudes and conditions, to determine which is correct.

Question 3 How significant are the effects of atmospheric waves and tides propagating from below on the thermospheric temperature structure? 
Atmospheric tides are global-scale waves whose periodicities correspond to harmonics of 24 hours. A wide spectrum of tides exists, some of which propagate upward into the thermosphere from their source regions in the lower and middle atmosphere, while others are generated in situ in the thermosphere by absorption of solar UV and EUV. Tides are a major source of winds and temperature variations in the lower thermosphere, and they play a major role in the generation of ionospheric Electric fields through the E-region dynamo. Previous studies (e.g. Lastovicka 2006; England et al. 2006) have estimated that large-scale atmospheric waves such as tides are responsible for $\sim 40 \%$ of the variability in the ionosphere at low latitudes. Upward-propagating tides vary in response not only to changes in their forcing, such as by tropospheric convective activity, but also to changes in conditions of the middle atmosphere through which they propagate.

Observations by the TIMED satellite (e.g., Zhang et al. 2006; Forbes et al. 2008; Oberheide and Forbes 2008) have identified the main tides that propagate from the lower atmosphere to the base of the thermosphere and have determined their variability with season, the quasi-biennial oscillation, and even El Niño. However, observations between the altitudes of $\sim 110 \mathrm{~km}$ (e.g., from TIMED) and $400 \mathrm{~km}$ (e.g., from CHAMP) are far less complete. Recently, Talaat and Lieberman (2010) analyzed WINDII data to show that tides penetrate into the middle thermosphere with amplitudes large enough to be observed by GOLD. Further, temperatures observed with the ENVISAT-MIPAS at altitudes up to $150 \mathrm{~km}$ have been used to identify a portion of the diurnal tidal spectrum that is seen just below the altitudes where GOLD will observe (García-Comas et al. 2016). Unlike observations made from low-Earth orbit, GOLD will be able to observe the temporal and spatial changes simultaneously. GOLD will stare at locations on the ground, observing the variability of tides for days. Such extended sampling at a location is similar to that provided by ground-based observations. However, GOLD will make simultaneous observations over a large geographical region, enabling a synthesis of measurements in a manner analogous to a ground-based network, but with the advantage of identical coverage over both land and sea. The GOLD mission will address this question by examining two more specific issues:

(a) which atmospheric waves propagate from the mesopause region to the middle thermosphere and

(b) what is the daily and seasonal variability of waves in the middle thermosphere.

From model simulations and observations at lower altitudes, it is expected that only tides with the longest vertical wavelengths will reach $150-180 \mathrm{~km}$ altitude, producing temperature perturbations in the disk observations. Originally the NCAR TIEGCM only included semi-diurnal tides which provided a representation of lower atmosphere forcing of the thermosphere (Richmond et al. 1992); later versions use GSWM (Hagan et al. 1999) to incorporate a wider range of lower atmosphere forcing. As shown in Fig. 3, the largest amplitude tides at these altitudes are expected to produce significant variations in thermospheric temperature, $30 \mathrm{~K}$ or more, peak-to-valley. Given GOLD's uncertainty of $\sim 10 \mathrm{~K}$ for a two-hour imaging cadence, temperature changes from the larger amplitude tides in this altitude range should be identifiable.

Question 4 How does the nighttime equatorial ionosphere influence the formation and evolution of equatorial plasma density irregularities?

Plasma density irregularities at low latitudes and the ionospheric scintillations they cause, also known as "ionospheric bubbles," are produced in the post-sunset ionosphere by the 
Fig. 3 Simulated temperature difference map calculated by the TIE-GCM, with and without tidal forcing at the lower boundary. Line-of-sight temperatures from geostationary orbit correspond to $\sim 160 \mathrm{~km}$ altitude

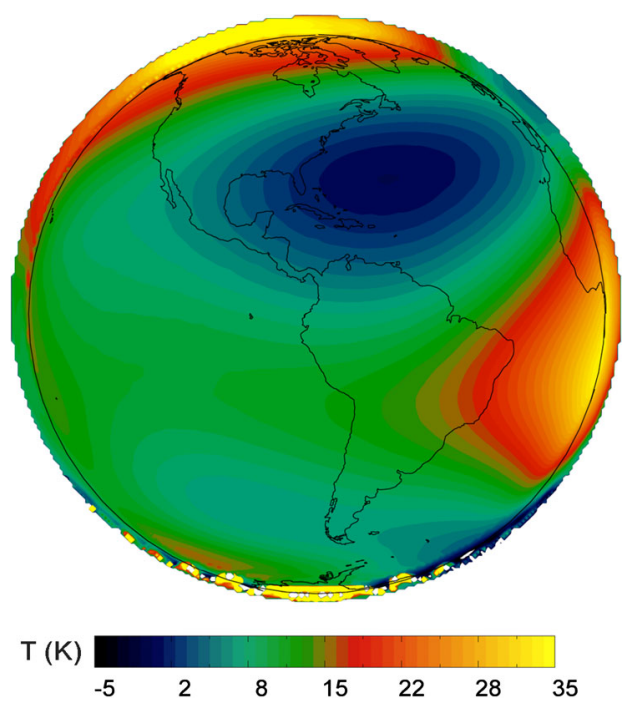

Rayleigh-Taylor (R-T) instability. The growth of the R-T instability into large-scale ionospheric bubbles has a significant optical signature (e.g., Weber et al. 1978; Tinsley et al. 1997; Kelley et al. 2003; Kil et al. 2004; Ledvina and Makela 2005) and is the greatest source of ionospheric irregularities at low latitudes (e.g., Martinis et al. 2005, 2009; Martinis and Mendillo 2007; Krall et al. 2009).

While bubble occurrence rates are known to depend on the state of the low latitude ionosphere-which is affected by geomagnetic storms, thermospheric tides, and other processes - the individual contributions are still unclear. During geomagnetic storms, changes in the high-latitude electric potential penetrate to the equatorial region, modifying its electrodynamics and drift velocities. The vertical drift velocities control the height, intensity, and separation of the equatorial ionization anomalies. Geomagnetic disturbances also alter the neutral winds which influence the electric potential and the latitude distribution of the anomalies. Tides and planetary waves also affect the vertical drifts, resulting in F-region longitudinal structures of considerable interest (e.g., England et al. 2010). GOLD will measure the peak electron density $\left(N_{\max }\right)$ in the equatorial ionosphere at night, from the perspective of a fixed-longitude frame, providing a true time-evolving map on a global scale. The large-scale structure in $N_{\max }$ contains information on the intensity and distribution of vertical $\mathrm{E} \times \mathrm{B}$ drifts and the mechanisms that affect the formation of plasma density irregularities.

Space-based optical detection of ionospheric bubbles using FUV observations has been demonstrated from LEO, most prominently by the GUVI instrument on TIMED (Kil et al. 2004, 2009). Since the GUVI measurements are from a constant local time on any given night, they contain an inherent spatial-temporal ambiguity as the bubbles form and move. GOLD will observe ionospheric bubbles from a constant geographic frame, imaging the large-scale development of individual bubbles. This observing capability provides the means to tie bubble occurrence, drift, and evolution to the global-scale ionospheric morphology and hence to ionospheric electrodynamics.

This question will be addressed by using nighttime observations of the equatorial ionosphere to examine two more specific issues: 
(a) What factors in the configuration of the equatorial ionosphere influence the formation of ionospheric bubbles and

(b) What is the persistence of ionospheric bubbles as they evolve and drift?

The formation of ionospheric bubbles depends on solar activity, geomagnetic activity, season, and longitude sector (e.g., Comberiate and Paxton 2010), and may depend on lower atmospheric conditions, including gravity wave activity, as well. The effect of geomagnetic activity is particularly complex, but the longitude where post-sunset bubbles are formed can be specifically related to the timing of a storm (Aarons 1991; Martinis et al. 2005; Basu et al. 2007). GOLD images will create nightly maps of bubbles over $\sim 100^{\circ}$ of longitude during the period that bubbles form ( 2000-2200 LT), enabling comprehensive comparisons of bubble occurrence rates and the state of the T-I system.

Bubble drift rates are one phenomena that GOLD is well suited to examine. During geomagnetically quiet times, ionospheric bubbles drift eastward due to the eastward motion of the nighttime F-region ionosphere (Martinis et al. 2003). These post-sunset eastward drift velocities have been measured from the ground (by imagers and radars) and from space (by the IMAGE satellite; Park et al. 2007). However, during geomagnetic storms, the bubbles have been observed to drift westward in the middle of the night (Martinis et al. 2003; Martinis et al. 2015). GOLD observations of drifting bubbles will uniquely determine the sense of the bubble drift direction as a function of longitude under all geomagnetic conditions, both quiet and disturbed. The persistence of individual plasma depletions can also be uniquely determined by GOLD nighttime observations. It is also possible that new bubbles can be created away from the post-sunset production region, possibly triggered by existing bubbles, as in the model simulations of Huba and Joyce (2010). This process, if it occurs, cannot be discerned from ground-based or LEO observations, but GOLD can observe it unambiguously. GOLD will also be able to relate bubble drift and persistence to observations of the large-scale variability driven by storms and waves discussed under Questions 1 and 3.

\section{Mission Design}

To obtain the viewing perspective desired for the GOLD mission, a host in geostationary orbit was needed. While NASA missions of opportunity have typically flown on satellites dedicated to science missions, the opportunities for launch into geostationary orbit aboard a mission dedicated to science have been rare. However, there are numerous communications satellites in such orbits. The GOLD mission was proposed with a commercial partner, SES Government Solutions (SES GS), who will fly the imager (host it) on the SES-14 satellite (shown at the top of Fig. 4). Two other essential components of the mission, the instrument (middle image in Fig. 4) and science investigation are led by LASP/CU and FSI/UCF respectively.

\subsection{Host Mission}

As mentioned above, through an agreement with SES GS the GOLD imager will fly as a hosted payload on the SES-14 satellite, which is being launched by, SES the parent company of SES GS. SES is a leader in satellite communications with decades of experience in owning and operating satellites in geostationary orbit. SES-GS has successfully hosted optical instruments - e.g., the Commercially Hosted Infrared Payload (CHIRP) for the Department of Defense - on their geostationary, communications satellites. SES and SES-GS 

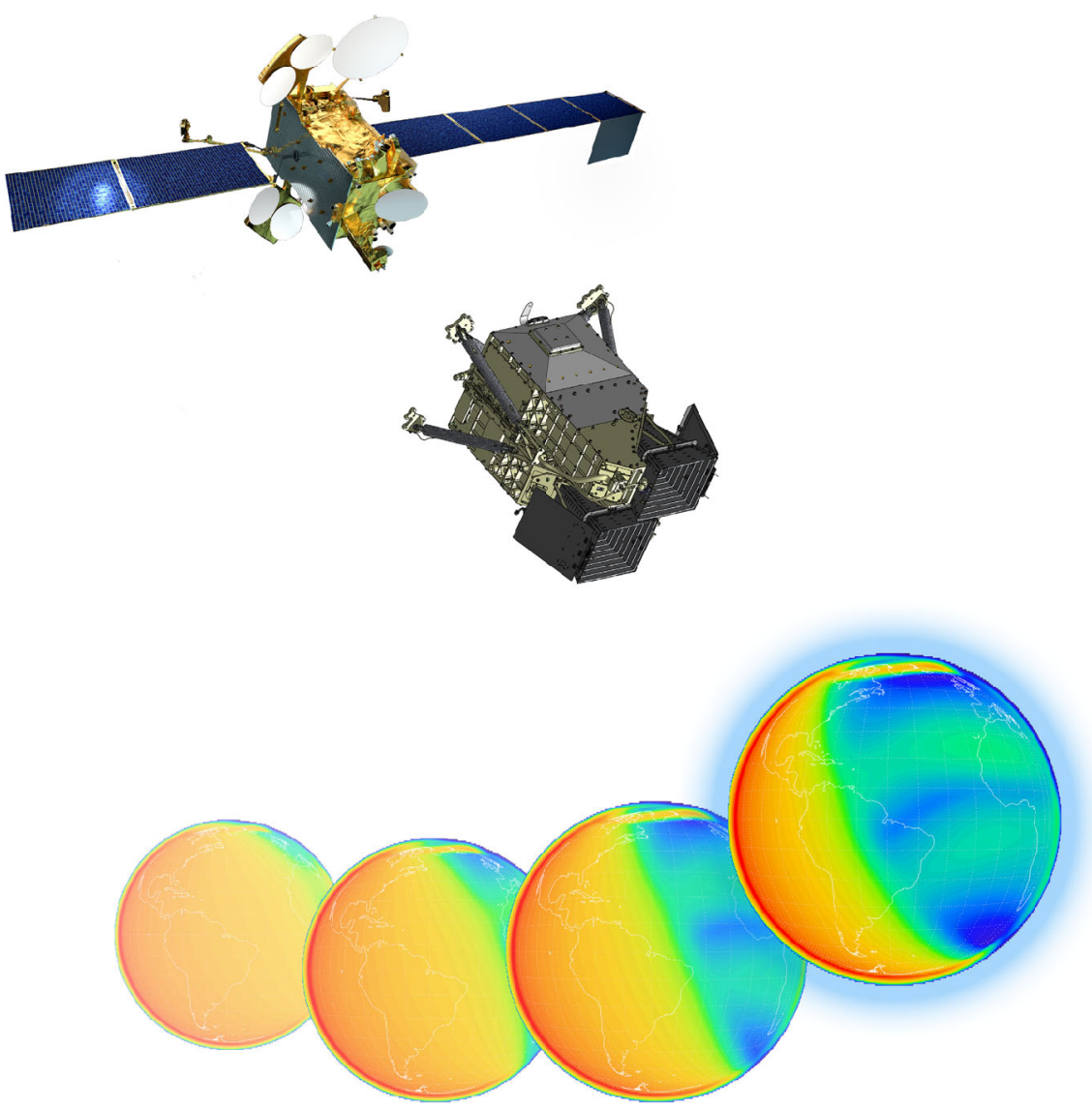

Fig. 4 The GOLD Mission: (top) Artist's rendering of the SES-14 satellite. (middle) Drawing of the GOLD imager built by LASP/CU. (bottom) Simulated images of Earth's emission brightness at $135.6 \mathrm{~nm}$, primarily from atomic oxygen, as observed from a geostationary orbit at $47.5^{\circ}$ west longitude where the GOLD imager will be stationed. The simulations shown are computed using the Global Airglow model with neutral and ion densities from the NCAR Thermosphere-Ionosphere-Electrodynamics General Circulation Model. These images of the Earth are calculated for 21 December of an arbitrary year at solar maximum, but with low geomagnetic activity. In this image emissions from the dayside, nightside and the aurora (northern hemisphere) are visible. Brightness variations across the dayside range from $\sim 10 \mathrm{kR}$ (red) to $\sim 100 \mathrm{R}$ (green). The blue areas shown on the nightside of the Earth correspond to 10 to $100 \mathrm{R}$

will operate the satellite, uplink instrument commands generated by the GOLD team, and transfer downlinked data to GOLD facilities for processing and distribution to the science community and other users. For decades, SES has produced reliable satellites that have typically operated on-orbit for 15 years or more. The SES-14 spacecraft, a Eurostar 3000e, was built by Airbus Defense and Space (Airbus DS). The spacecraft is scheduled for launch on a SpaceX Falcon 9 in late 2017. After launch, the spacecraft is designed to use electric propulsion for transfer to geostationary orbit at $47.5^{\circ} \mathrm{W}$ longitude and for station-keeping.

Once the satellite is on station, commands will be uplinked through an SES Mission Operations Center (MOC) which will also monitor the satellite and the GOLD instrument. More extensive monitoring of the data from the instrument will be conducted by the SOC at LASP/CU which will also generate the commands. GOLD data are not stored aboard the 
Fig. 5 Drawing of the GOLD imager

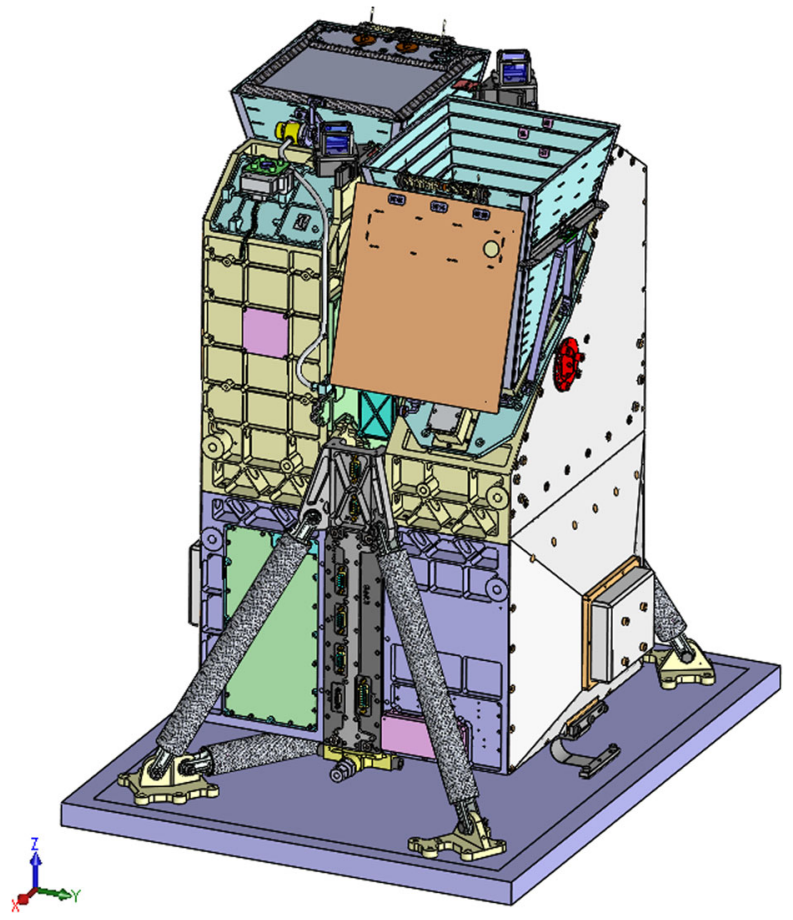

satellite but are routed to a transponder to be immediately downlinked to an SES ground station in Virginia, USA. Consequently, the typical latencies for the lowest level GOLD data products is expected to be less than one hour. Processed data will be available to the science community through the GOLD Science Data Center (SDC) at UCF. The data will also be available to drive and improve space weather nowcasting and forecasting capabilities.

\subsection{GOLD Imager}

The Far Ultraviolet (FUV) imager that the GOLD mission will fly (Fig. 5) was built at LASP/CU. It has two identical and independent channels, each capable of performing every required measurement. Each channel has a plane scan mirror-two sided and slightly tilted such that one side scans northern latitudes and the other southern-enabling a single channel to scan the entire disk of the Earth by rotating the mirror through $\sim 180$ degrees. Each channel also has three entrance slits-providing $0.21,0.35$ or $2.16 \mathrm{~nm}$ resolution. The slits were selected to match observational capabilities needed for the mission. Each channel contains an imaging, photon counting detector, and the communications bandwidth available enables the position and pulse height of each photon detection to be downlinked as the events occur. The data are stored at the ground station until transmission to LASP is confirmed. Binning and averaging are performed only during processing on the ground, which maximizes the analysis flexibility. Additional details for the instrument are provided later in this paper.

\subsection{Data Processing}

The University of Central Florida (UCF) is the lead institution for the GOLD mission and is responsible for the science investigation. The GOLD Science Data Center (SDC) will be 
located at University of Central Florida (UCF). While the Science Operations Center (SOC) at LASP will perform checks on the Level 0 data and generate time tagged (Level 1A) data, the SDC produces the remaining data products and is capable of generating Level 1A data if needed.

\section{Observations/Measurements by the GOLD Mission}

The mission will use proven remote sensing techniques to derive the temperature, density and composition of the Earth's space environment. More specifically, the information obtained from the observations, in addition to the brightness of Earth's FUV emissions, are:

On the disk:

- Neutral temperature, during the day, from $\mathrm{N}_{2} \mathrm{LBH}$ band rotational structure.

- $\mathrm{O} / \mathrm{N}_{2}$ column density ratios, during the day, from atomic oxygen $135.6 \mathrm{~nm}$ and $\mathrm{N}_{2} \mathrm{LBH}$ emission intensities.

- Solar proxy, during the day, from the brightness of the FUV emissions.

- Peak electron density, during the night, from radiative recombination of $\mathrm{O}^{+}$resulting in the atomic oxygen emission at $135.6 \mathrm{~nm}$.

On the limb:

- Exospheric neutral temperature, during the day, from $\mathrm{N}_{2} \mathrm{LBH}$ emission profiles.

- $\mathrm{O}_{2}$ density profiles, during day and night, from stellar occultation.

Each of these is available as a Level 2 (L2) data product. The processing done to obtain them is summarized in Table 1. Level 2 and higher data products range from measurements converted to geophysical units (counting rates converted to emission brightnesses) to ones requiring modeling or fitting of data. They include both disk and limb products. The disk products can be produced pixel by pixel, while the limb products can be produced profile by profile. Level 2 products include $\mathrm{O}$ and $\mathrm{N}_{2}$ emission brightnesses, in addition to the six data products listed above. Distribution and local archiving of the GOLD data is also provided by the SDC which will supply data to the Space Physics Data Facility (SPDF), the NASA designated archive.

The uncertainties, spatial resolution, temporal coverage and time coverage that the measurements are required to satisfy in order for the mission to meet all the objectives are summarized in the Level 1 science requirements for the GOLD mission, which are listed Table 2.

Table 1 GOLD science data levels

\begin{tabular}{ll}
\hline Level & Brief description \\
\hline 1A & Time tagged data \\
1B & Binned and mapped in GOLD coordinates \\
1C & Calibrated and geolocated data \\
1D & Quick-look plots \\
2 & $\mathrm{O}_{\mathrm{N}}, N_{\max }, Q_{\mathrm{EUV}}, \mathrm{T}($ disk$), \mathrm{T}(\mathrm{limb}), \mathrm{O}_{2}$ density profiles, \\
& emission brightnesses \\
3 & $\begin{array}{l}\text { Multiple orbits and images of all parameters, more extensively } \\
\text { modeled L2 data }\end{array}$ \\
4 & Higher level analysis and images \\
\hline
\end{tabular}


Table 2 Baseline (level 1) science requirements

1. GOLD shall make disk images of atomic oxygen $(\mathrm{O}) 135.6 \mathrm{~nm}$ emissions and molecular nitrogen $\left(\mathrm{N}_{2}\right)$ Lyman-Birge-Hopfield ( $\mathrm{LBH}$ ) emissions over a latitude range of $\pm 60^{\circ}$ and a longitude range of $\pm 70^{\circ}$ relative to spacecraft nadir

2. GOLD shall construct, on the sunlit portion of the disk, images of:

a. lower thermosphere temperature with a precision of $55 \mathrm{~K}$ with 60 minute cadence and spatial resolution of $250 \mathrm{~km} \times 250 \mathrm{~km}$ (at nadir); and

b. thermosphere column composition $\left(\mathrm{O} / \mathrm{N}_{2}\right.$ radiance ratio) with a precision of $10 \%$ with 30 minute cadence and spatial resolution of $250 \mathrm{~km} \times 250 \mathrm{~km}$ (at nadir)

3. GOLD shall construct, on the nighttime portion of the disk, images of $N_{\max } \mathrm{F} 2$, at the peak of the equatorial arcs, with a precision of $10 \%$ and a latitude resolution of $2^{\circ}$

4. GOLD shall track ionospheric bubbles (depletions) within a single equatorial arc with a precision of $20 \%$ in brightness and a spatial resolution (at nadir) of $100 \mathrm{~km}$ in the longitudinal direction

5. GOLD shall measure near-equatorial limb profiles of the $\mathrm{N}_{2} \mathrm{LBH}$ emissions up to an altitude of approximately $350 \mathrm{~km}$

6. GOLD shall measure exospheric temperature (near-equatorial) with a precision of $40 \mathrm{~K}$ in the daytime

7. GOLD shall measure $\mathrm{O}_{2}$ line-of-sight column densities at an altitude of $160 \mathrm{~km}$ with a precision of $10 \%$ and a vertical resolution of $10 \mathrm{~km}$ in the nighttime and daytime by stellar occultation

8. GOLD shall perform all of the above from geostationary orbit for two years

The intrinsic capability of the instrument exceeds that necessary to meet the requirements summarized in Table 2. The spatial resolution capability in the longitudinal direction, is either $\sim 40 \mathrm{~km}$ or $100 \mathrm{~km}$ for observations of atmospheric emissions, depending on which slit (of the two included for disk observations) is used (resolution during occultations depends on the timing accuracy). In the latitudinal direction the spatial resolution is $\sim 50 \mathrm{~km}$. During processing the photon events are binned spatially. This improves the signal to noise ratios and decreases the uncertainties to less than those listed in Table 2.

The instrument is designed to meet the requirements for observations of the sunlit disk during solar minimum $(\mathrm{F} 10.7=70)$ at high, 70 degrees SZA and nadir viewing, approximately the worst-case solar illumination and viewing conditions. At the beginning of operations the Sun is expected to be near solar minimum. The instrument is also fully capable of observations at solar maximum.

GOLD measurements will be used with some of the most advanced space environment models available (e.g. TIE-GCM and CTIPe). The GOLD mission provides a continuous data set, over a large part of the T-I system, that is ideal for improving such large scale models and developing new ones.

\section{The GOLD Imager}

The GOLD mission uses a pair of independent, identical channels that interface to the SES14 spacecraft through a single processor assembly. Each channel is an independently commandable, imaging spectrograph that can measure the Earth's airglow emissions from 132 to $162 \mathrm{~nm}$. This wavelength coverage, at the spectral resolution planned for the observations, enables the use of existing remote sensing techniques for retrieving densities, composition and temperature. The baseline mission is two-years of operations with both channels performing the measurements summarized in Table 2 and with sufficient data completeness to determine the seasonal variability. 
Fig. 6 Instrument Layout (one of two channels)

Table 3 GOLD instrument summary

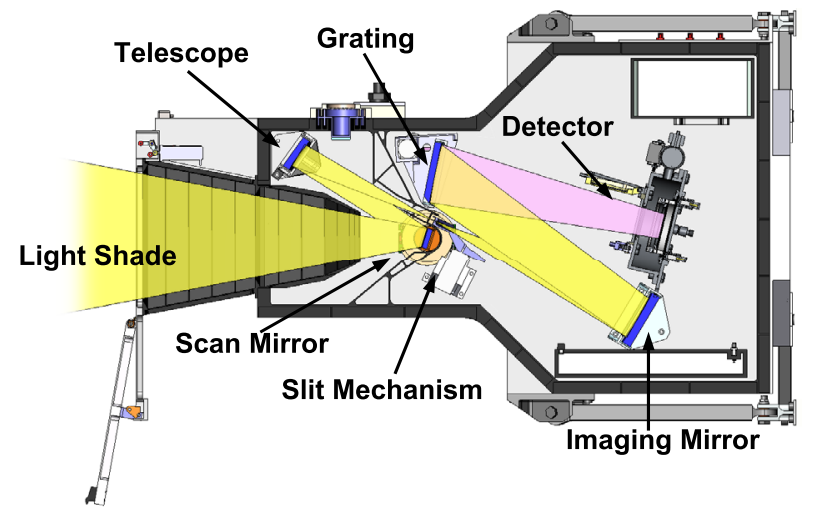

\begin{tabular}{ll}
\hline Resources (total) & \\
Mass & $37 \mathrm{~kg}$ \\
Power & $72 \mathrm{~W}$ (average) \\
Data Rate & $6 \mathrm{Mbits} /$ second \\
Telescope (each) & \\
Focal length (mm) & 150 \\
Entrance pupil size (mm) & $30 \times 30$ \\
Scan Mirror (each) & \\
Angular range & $\pm 100^{\circ}$ \\
Spectrograph (each) & \\
Wavelength Coverage (nm) & $132-162$ \\
3-Position Slits (each) & \\
Slit widths (mm) & $0.2,0.4,2.6$ \\
Spectral resolution (nm) & $0.20,0.35,2.2$ \\
Field of View (degrees) & $(0.05,0.15,0.95) \times 10.0$ \\
Detectors (each) & \\
Detector size (mm) & \\
Pixel format & $27 \times 32$ \\
\hline
\end{tabular}

Figure 6 shows the optical layout for one of the two identical channels and Table 3 summarizes the resource requirements for the total instrument and describes some of the important channel characteristics. In each channel a plane scan mirror is located in front of a spherical telescope mirror with a $150-\mathrm{mm}$ focal length, which images the Earth onto a spectrograph entrance slit. A concave toroidal mirror redirects the light passing through the slit before it impinges on a concave toroidal grating. The grating disperses the input beam and forms a spectral $\times$ spatial image of the slit on an 'open faced' microchannel plate (MCP) detector equipped with an opaque CsI photocathode and a cross-delay line (XDL) anode (Siegmund et al. 2004). A 3-position mechanism inserts a $0.2 \mathrm{~mm}, 0.4 \mathrm{~mm}$, or $2.6 \mathrm{~mm}$ wide entrance slit into the telescope focal plane.

GOLD's field-of-regard (FOR) is $31.0^{\circ} \mathrm{E}-\mathrm{W}$ and $19.75^{\circ} \mathrm{N}-\mathrm{S}$. This FOR enables each channel to image the disk over $\sim 160^{\circ} \times \sim 160^{\circ}$ (latitude $\times$ longitude) as well as perform limb scans and occultations to altitudes of $600 \mathrm{~km}$ (at the equator). This FOR also accom- 
modates a requirement that the spacecraft's earth-pointing axis may be adjusted by up to $\pm 5^{\circ} \mathrm{E}-\mathrm{W}$ and $\pm 1^{\circ} \mathrm{N}-\mathrm{S}$ in order to optimize its communications payload.

\section{Science Observing Profile \& Instrument Operations}

Spectroscopic observations by each channel of the GOLD instrument will be in one of three modes-high spectral resolution, HR $(0.2 \mathrm{~mm}$ slit); low spectral resolution, LR $(0.4 \mathrm{~mm}$ slit); or occultation, OCC (2.6 mm slit). HR mode provides the spatial resolution necessary for limb altitude profiles; disk images can be made in either HR or LR mode, depending on the desired tradeoff between spectral resolution and signal-to-noise; and stellar occultations will be performed in OCC mode. There is also a "Solar Safe" mode, which will be used when the Sun is within $30^{\circ}$ of the instrument field of regard (FOR), (approximately \pm 3 hours around local midnight). An diagram of the nominal observations performed during a day is shown in Fig. 7.

As depicted in Fig. 8, the scan mirror in each channel sweeps its field-of-view (which depends on the spectrograph entrance slit used) across the limb and disk, building up spatialspectral image cubes beginning at 0300 hours and ending at 2100 hours Satellite Local Time (SLT). At each mirror position, the detectors record the $x-y$ locations of individual photons as they arrive at the spectrograph focal plane. On the ground these locations are binned into $800 \times 600$ spectral-spatial arrays associated with each mirror position, providing $0.02^{\circ}$ along-the-slit spatial sampling and $\sim 0.04 \mathrm{~nm}$ spectral sampling. Further summing and binning occurs during ground processing to produce spectral-spatial image cubes summarized in Table 2.
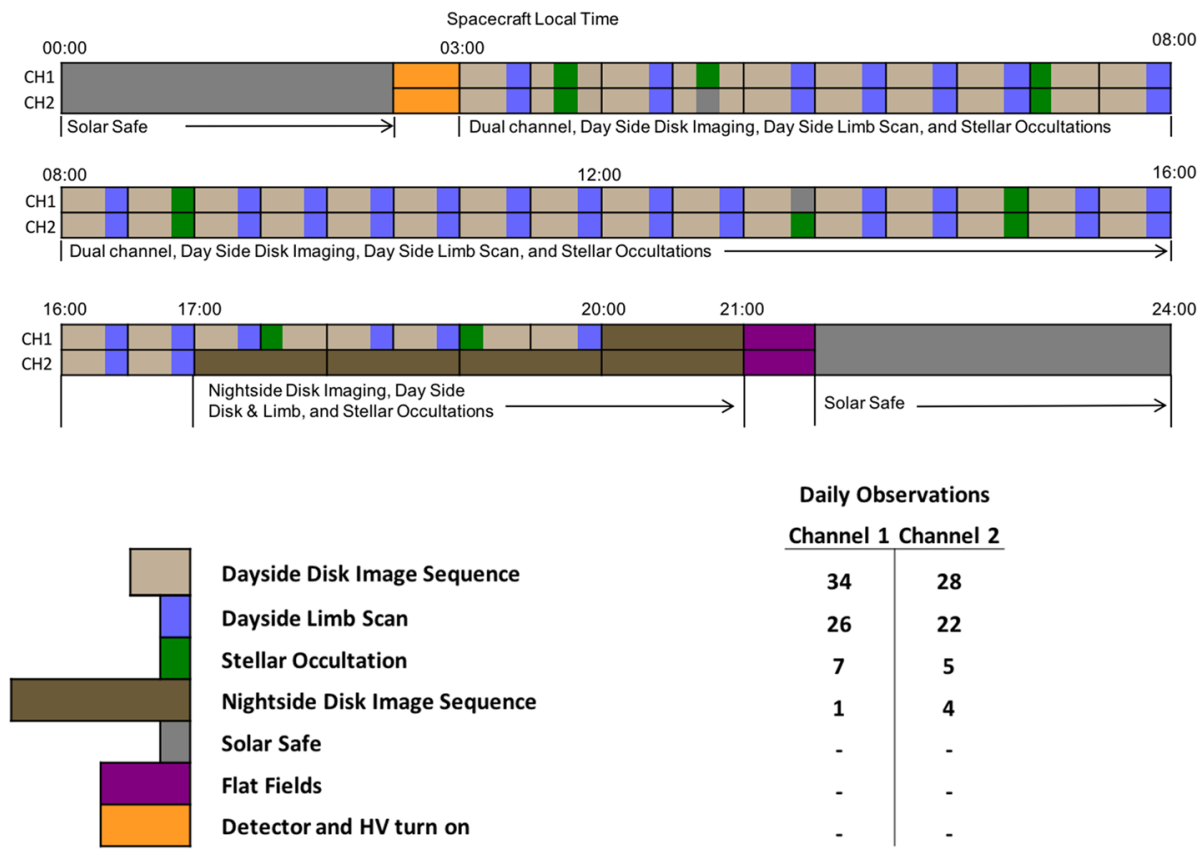

Fig. 7 Example of observations by channels 1 and 2 ( $\mathrm{CH} 1$ and $\mathrm{CH} 2)$ through 24 hours 

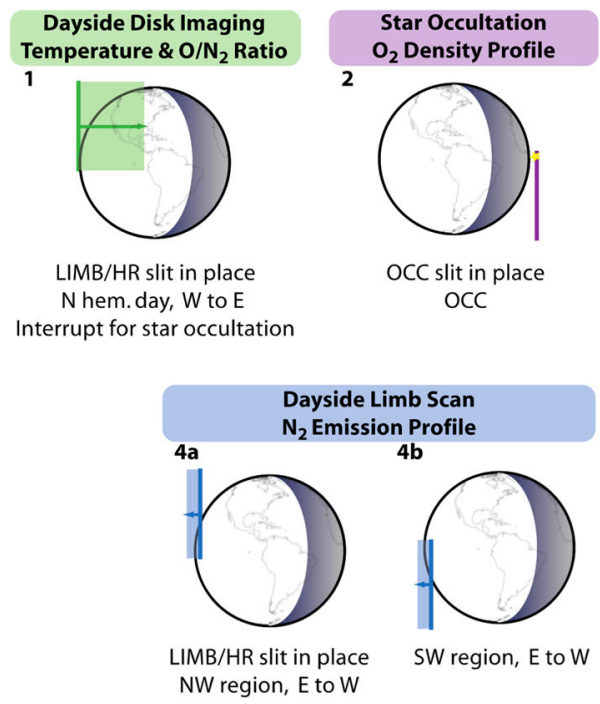

$\mathrm{O}_{2}$ Density Profile

2

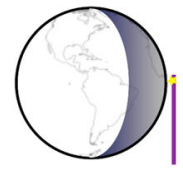

OCC slit in place OCC
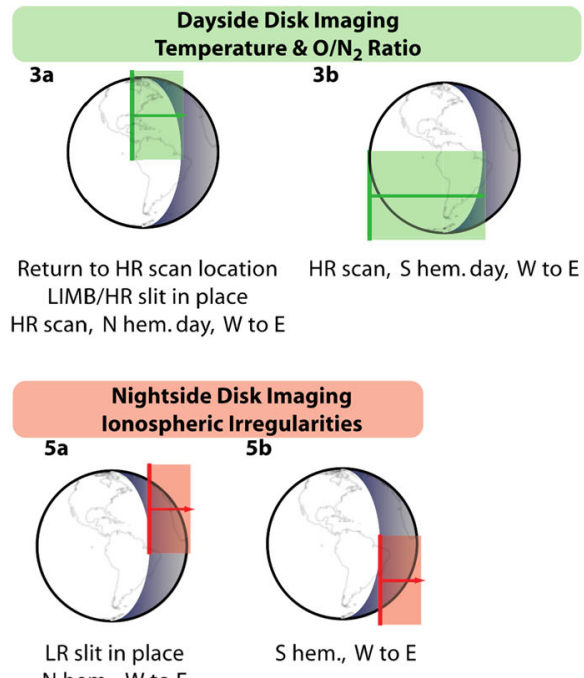

$\mathrm{N}$ hem., $\mathrm{W}$ to $\mathrm{E}$
LIMB/HR slit in place

HR scan, $N$ hem. day, W to $E$

Fig. 8 Observing scenario. Sunlit disk imaging in both hemispheres ( $3 a$ and $3 b$ ) for temperature and $\mathrm{O} / \mathrm{N}_{2}$ is followed by dayside limb scans of $\mathrm{N}_{2}$ emission in both hemispheres ( $4 a$ and $4 b$ ). Nightside $\mathrm{O}$ emission is imaged in both hemispheres $(5 a$ and $5 b)$. Occultations (2) interrupt disk imaging (1). Imaging resumes after occultation $(3 a$ and $3 b)$

Science and engineering data from the instrument are routed to a dedicated transmitter for immediate downlink to an SES ground station, from which they are transmitted to the LASP Science Operations Center (SOC). There the engineering data are displayed in real time to monitor instrument health and safety. Level 1A science data are produced and transmitted to the GOLD Science Data Center (SDC) at UCF. In addition, a subset of GOLD critical engineering data is routed to the spacecraft over a 1553 interface and downlinked in real time as part of the spacecraft housekeeping data stream to the spacecraft Mission Operations Center (MOC), also referred to as the Satellite Control Center (SCC), for monitoring of the instrument by SES. Commands to the instrument are transmitted over the same 1553 interface after being uplinked from the MOC

Dayside disk imaging and dayside limb scans are performed by sweeping the instantaneous field-of-view of each spectrometer across the sunlit disk in two swaths. One swath covers the northern latitudes and the other covers the southern (Panel 3a and 3b of Fig. 8). Scan rate and range of travel vary with SLT to ensure that the desired areas are observed and that each swath is completed in the $\sim 12$ minutes available ( 24 minutes to image the sun-lit part of the disk) aside from the limb observations. The maximum rate of $0.025^{\circ}$ per second (ground speed of $15.6 \mathrm{~km}$ per second at the sub spacecraft point) occurs at noon SLT.

In addition to the disk observation performed on the dayside, GOLD also makes either dayside limb scans or a stellar occultation each half hour. As shown in Fig. 8, dayside limb scans are made in both the northern and southern hemispheres (Panels $4 \mathrm{a}$ and $4 \mathrm{~b}$ ). The scans begin on the disk at a tangent altitude of $-50 \mathrm{~km}$ at the equator and scan to $\sim 430 \mathrm{~km}$ with a step size of $12 \mathrm{~km}$. Approximately 6 minutes is required to complete the scans. The order of scanning (e.g., limb-disk) and the scan direction (either east-west or west-east) for the disk and limb are programmable, as is the scan rate. Background contributions from dark counts and radiation are also measured each half hour by turning the scan mirrors to block 
photons for 30 seconds. The entire sequence—limb, disk and dark measurements—is timed to complete in 30 minutes.

Exceptions to the limb scan sequence occur when stars selected for occultation measurements pass through either limb (Panel 1) during a 30-minute observing period. In those cases the limb scan is omitted and the disk scan is interrupted to slew the FOVs to the star and the slit mechanism inserts the $1^{\circ}$ wide slit to perform the occultation (OCC mode). Occultations (Panel 2 of Fig. 8) require $\sim 7-8$ minutes to execute. The occultation slit is wide enough to allow the scan mirror (and slit image) to be held stationary for the entire occultation. Once the occultation is complete, the scan mirror returns to its point of departure from the imaging observation, and the disk scan is resumed (Panel 3a of Fig. 8). Since limb scans will be skipped when an occultation is performed during a 30-minute observing period, the impact on the time devoted to disk imaging is insignificant. Approximately 10 occultations per day are anticipated.

At 1700 SLT, one channel continues dayside observations while the other begins nightside observations (Panels 5a and 5b of Fig. 8). Beginning at 2000 SLT the second channel is also dedicated to scanning the night side, increasing cadence by a factor of 2 . The nightside scans begin $\sim 15^{\circ}$ in longitude behind the terminator and extend up to $75^{\circ}$ eastward. During the last hour of observations (2000-2100 SLT) all limb observations will be omitted in order to improve the SNR of the disk images.

\section{Observations}

All the observations are spectrally resolved data at wavelengths of $132-162 \mathrm{~nm}$. A model calculation of the daytime airglow spectrum at these wavelengths is shown in Fig. 9. The spectrum contains the emissions, from atomic oxygen at $135.6 \mathrm{~nm}$ and the $\mathrm{N}_{2}$ Lyman-BirgeHopfield bands, used by the GOLD mission for remote sensing of the T-I system. A spectrum of this wavelength region will be assembled for each pixel on the dayside.

At night the $135.6 \mathrm{~nm}$ atomic oxygen emission, which persists due to production by recombination of the ionosphere, will be used to derive information about the nighttime ionosphere.

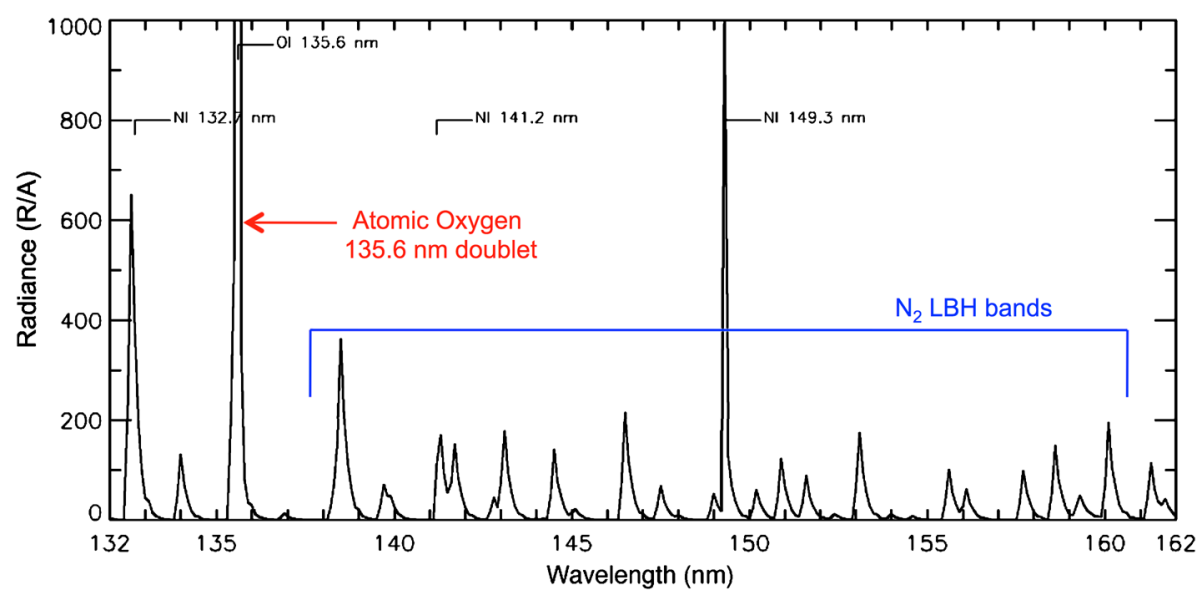

Fig. 9 Daytime far-ultraviolet (FUV) model airglow spectrum 


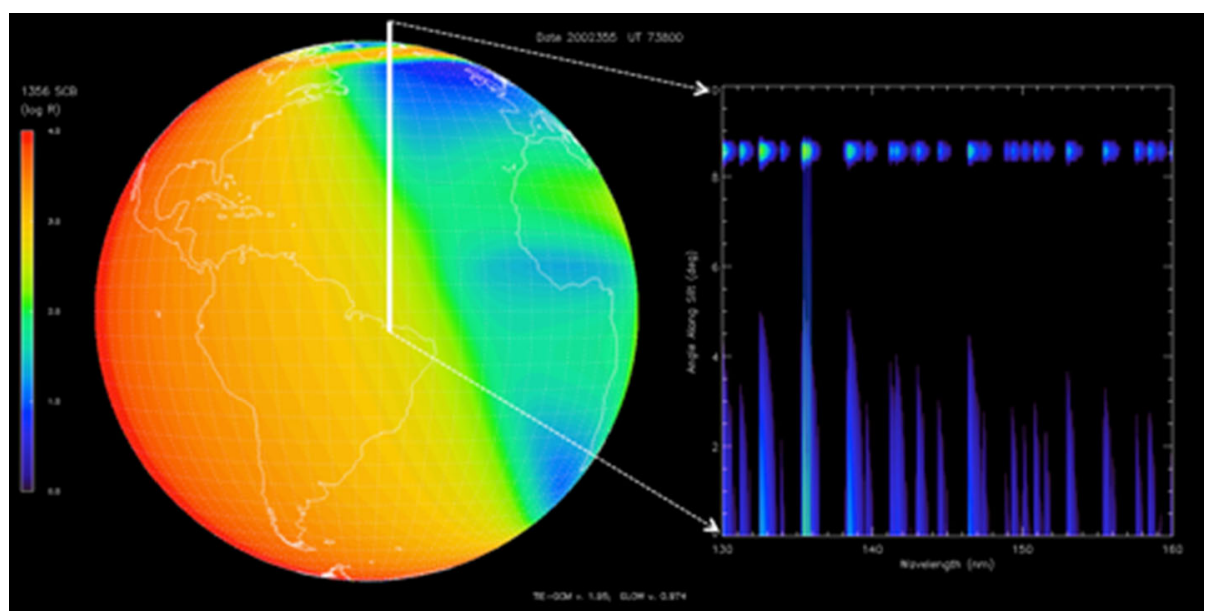

Fig. 10 Left: Representation of Earth's emissions at $135.6 \mathrm{~nm}$ calculated using atmospheric densities from the TIE-GCM model and radiances calculated by the GLOW code, with an image of the entrance superimposed in white (vertical rectangle). Right: Model spectrum that would be detected when viewing the atomic oxygen $(\mathrm{O})$ and molecular nitrogen $\left(\mathrm{N}_{2} \mathrm{LBH}\right.$ bands) emissions within the entrance slit

As discussed in the previous section, GOLD assembles spatial-spectral image cubes by sweeping the field-of-view of each channel across the Earth. A depiction of one instantaneous slit position is show on the left side of Fig. 10 as a white rectangle superimposed on the simulated image of oxygen $135.6 \mathrm{~nm}$ emission. A simulation of the Earth's spatially resolved spectrum along the slit, which contains both $135.6 \mathrm{~nm}$ emission and LBH 132$162 \mathrm{~nm}$ emission, is shown on the right side of Fig. 10. Since the slit is projected onto the Earth near sunset (the terminator is diagonal across the earth) the spectrum shows significant spatial variation. At the lower latitudes, the dayglow emissions from atomic oxygen and molecular nitrogen are both seen. At slightly higher latitudes, where the slit images the night side, only the atomic oxygen $135.6 \mathrm{~nm}$ emission is seen. Near the top, the slit crosses the auroral region, which produces the brightest emissions observed in the spectrum.

GOLD will also measure the limb brightness profile at the equator on the dayside every 30 minutes, unless an occultation is scheduled during the period. The shape of the $\mathrm{N}_{2}$ limb emission profile varies with exospheric temperature and will be used to derive the temperature. Since the tangent points observed on the limb are fixed in longitude, the exospheric temperature changes at the equator can be tracked throughout the day and from day to day. From the planned orbit of the SES-14 satellite, geostationary at $47.5^{\circ} \mathrm{W}$ longitude, the tangent points at the equator will be located at approximately $129^{\circ}$ West and $34^{\circ}$ East longitude. A model simulation of the $\mathrm{N}_{2}$ limb emission profile data from GOLD is shown in Fig. 11, as well as a fit to the simulated data.

While $\mathrm{O}_{2}$, one of the three most abundant constituents of the Earth's thermosphere, does not have emissions at the wavelengths observed by the GOLD imager, it does absorb photons at those wavelengths. Consequently, occultations of ultraviolet stars rising or setting through the Earth's limb can be used to determine the $\mathrm{O}_{2}$ densities. Shown is Fig. 12 are some simulated retrievals of $\mathrm{O}_{2}$ densities from occultations by the GOLD imager. The signal to noise and uncertainty in the retrieved densities depends on the brightness of the star being observed, as demonstrated by the three signal to noise levels (low, medium and high) shown. 
Fig. 11 Simulation of exospheric temperature retrieval from $\mathrm{N}_{2} \mathrm{LBH}$ bands

(140-160 nm) using model fits to the topside $(>200 \mathrm{~km}$ ) profile.

Pluses: simulated data including Poisson noise and slit function. Red dotted line: initial guess using a Chapman type function (see text). Blue dashed line: final fit after iterative adjustment of Chapman function parameters

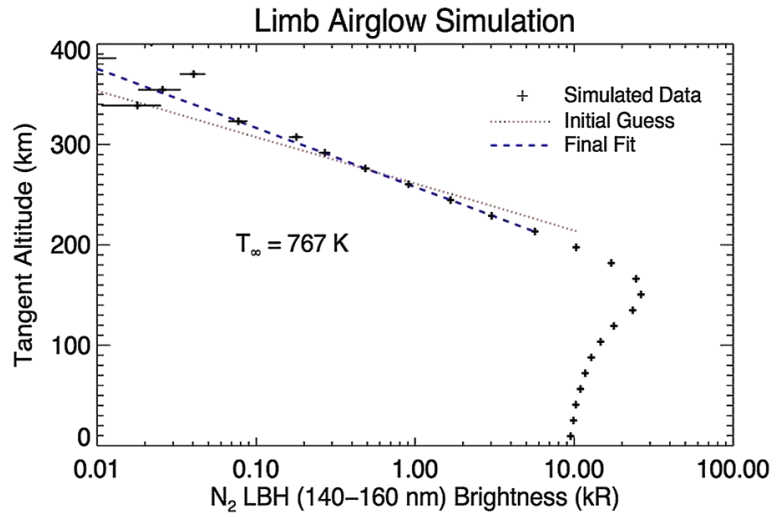

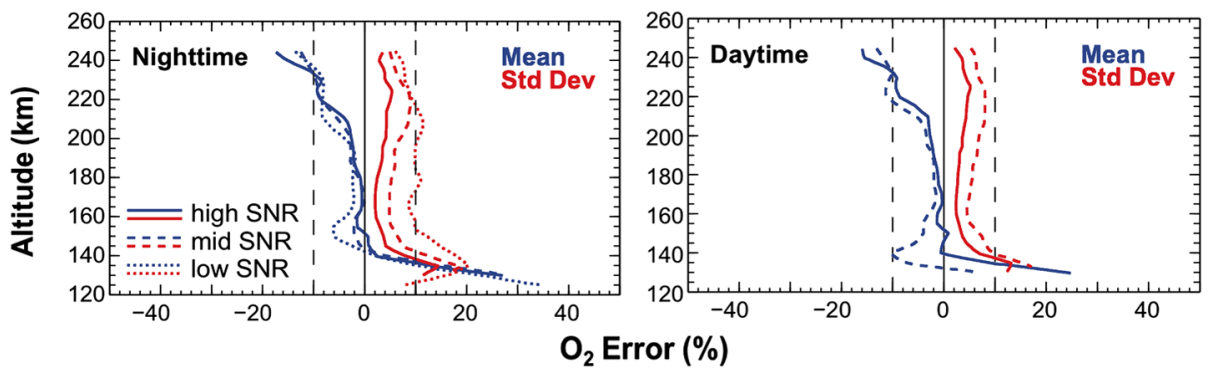

Fig. 12 Estimated accuracy (blue) and precision ( red) of the GOLD $\mathrm{O}_{2}$ density retrievals derived from simulations using measured stellar spectra. Results are grouped according to signal to noise level-high, medium or low

\section{Science Data Products}

The signals recorded when observing the Earth's atmosphere or a star are input for the algorithms used to derive GOLD's Level 2 and higher science data products, listed in Table 4. The lower level data products (Level 1 in Table 1) are generated directly from sensor data by first adding data (e.g., ephemeris, pointing and calibration) that is not included in data downlinked from the instrument, followed by combining of data records from the instrument. The Level 2 science data products will be produced after the measured ephemeris data are available, typically $\sim 1$ hour after the observations are completed. Table 4 provides some details for the Level 2 Science data products that will be produced. The timeline that the GOLD mission is committed to for production of data products is summarized in Table 5.

The data products will be produced at the GOLD Science Data Center (SDC) at the University of Central Florida, with the exception of L1A data which LASP will produce. The GOLD SDC will also provide public access to the science data products as will NASA's SPDF, the NASA designated archive for data from the mission.

\subsection{Algorithms to Produce Data Products}

The algorithms used to derive the Level 2 data products rely on proven remote sensing techniques. All of them have been used successfully with data from previous satellite missions. Neutral composition $\mathrm{O} / \mathrm{N}_{2}$ on the disk are derived using an algorithm that 
Table 4 Level 2 Science data products

\begin{tabular}{|c|c|c|c|}
\hline Data product & Description (units) & Cadence & Spatial coverage/resolution \\
\hline \multicolumn{4}{|l|}{ Level 2} \\
\hline $\mathrm{O} / \mathrm{N}_{2}$ & $\begin{array}{l}\text { Neutral composition. Ratio of } \\
\mathrm{O} \text { to } \mathrm{N}_{2} \text { vertical column } \\
\text { density (dimensionless) }\end{array}$ & 30 minutes & $\begin{array}{l}\text { Retrievals over the sunlit region } \\
\text { globe at } 250 \mathrm{~km} \times 250 \mathrm{~km} \text { resolution } \\
\text { (nadir) }\end{array}$ \\
\hline $\mathrm{T}$ & $\begin{array}{l}\text { Thermospheric neutral } \\
\text { temperature }(\mathrm{K})\end{array}$ & 60 minutes & $\begin{array}{l}\text { Retrievals over the sunlit region at } \\
250 \mathrm{~km} \times 250 \mathrm{~km} \text { resolution (nadir) }\end{array}$ \\
\hline$Q_{\mathrm{EUV}}$ & $\begin{array}{l}\text { Solar EUV flux proxy } \\
\left(\mathrm{mW} / \mathrm{m}^{2}\right)\end{array}$ & 1 minute & $\begin{array}{l}\text { No spatial dependence. Average four } \\
\text { L1C columns to capture temporal } \\
\text { dependence }\end{array}$ \\
\hline$T_{\text {exo }}$ & $\begin{array}{l}\text { Neutral exospheric } \\
\text { temperature }(\mathrm{K})\end{array}$ & $\begin{array}{l}30 \text { minutes (unless } \\
\text { occultation } \\
\text { replaces obs.) }\end{array}$ & $\begin{array}{l}2 \text { Longitudes: (E/W limbs); } \\
\text { Latitudes: } 10^{\circ} \mathrm{S}-10^{\circ} \mathrm{N} ; \text { Retrievals on } \\
\text { sunlit limb only }\end{array}$ \\
\hline $\mathrm{O}_{2}$ & $\begin{array}{l}\text { Molecular oxygen number } \\
\text { density profile }\left(\mathrm{mol} / \mathrm{cm}^{3}\right)\end{array}$ & $\begin{array}{l}\sim 12 \text { scans per } \\
\text { day at irregular } \\
\text { sampling }\end{array}$ & $\begin{array}{l}2 \text { Longitudes: (E/W limbs); } \\
\text { Latitudes: } 60^{\circ} \mathrm{S}-60^{\circ} \mathrm{N} \text {; Altitudes: } \\
\text { 130-250 km; SLT: 03-20 hours }\end{array}$ \\
\hline$N_{\max }$ & $\begin{array}{l}\text { Peak electron density } \\
\left(\text { electrons } / \mathrm{cm}^{3}\right)\end{array}$ & $\begin{array}{l}\text { Minimum of one } \\
\text { arc every } 20 \\
\text { minutes }\end{array}$ & $\begin{array}{l}\text { Coverage in the equatorial } \\
\text { anomalies; } 200 \mathrm{~km} \times 200 \mathrm{~km} \\
\text { resolution (nadir); LT: } 19-23 \text { hours }\end{array}$ \\
\hline
\end{tabular}

Table 5 Timeline for data product availability

\begin{tabular}{|c|c|c|}
\hline Step & Cumulative time & Comments \\
\hline Telemetry downlink & N/A & $\begin{array}{l}\text { Continuous contact, near real time data collection at } \\
\text { ground station }\end{array}$ \\
\hline $\begin{array}{l}\text { Data from ground station to } \\
\text { SOC }\end{array}$ & 15 minutes & $\begin{array}{l}\text { Data forwarded from ground station to the SOC within } \\
15 \text { minutes of receipt }\end{array}$ \\
\hline L0 to L1A processing & 1.25 hours & L1A produced at LASP within 1 hour \\
\hline $\mathrm{L} 1 \mathrm{~A}$ to $\mathrm{L} 1 \mathrm{C}$ processing & 30 days & L1A-L1C produced and validated within 30 days \\
\hline L1C to L2 processing & 60 days & $\begin{array}{l}\text { L2 produced and validated within } 30 \text { days, data } \\
\text { available upon validation }\end{array}$ \\
\hline L2 to $\mathrm{L} 3$ processing & 120 days & $\begin{array}{l}\text { L3 produced and validated within } 60 \text { days of L2 } \\
\text { products being available }\end{array}$ \\
\hline $\begin{array}{l}\text { Delivery of archival data } \\
\text { products to SPDF }\end{array}$ & 120 days & 180 days cumulative for first delivery \\
\hline
\end{tabular}

was developed by Computational Physics Inc. (CPI) and has been used with GUVI and SSUSI images (Strickland et al. 1995; Evans et al. 1995). Data from the GOLD mission has higher spectral resolution, which will allow atomic emission lines that overlap the $\mathrm{N}_{2} \mathrm{LBH}$ bands to be excluded. This algorithm has been extensively documented (e.g., Christensen et al. 2003; Strickland et al. 2004a, 2004b, 2012; Meier et al. 2005; Crowley et al. 2006; Zhang and Paxton 2011, 2012). Exospheric temperatures (Texo) are derived by fitting a three-parameter Chapman type function (Lo et al. 2015; Bougher et al. 2017) to the LBH radiance profile above $200 \mathrm{~km}$. The QEUV algorithm, which CPI originated, is based on the well-proven airglow modeling capabilities (AURIC and GLOW) that have been applied to previous missions, such as TIMED (Strickland et al. 1995, 2004a, 2004b, 2007; Evans et al. 1995). 
For temperatures on the disk the retrieval algorithm is an extension of one used previously with HITS data (Aksnes et al. 2006, 2007). Temperatures are retrieved by fitting the observed rotational structure of the $\mathrm{N}_{2} \mathrm{LBH}$ bands, using an optimal estimation routine. GOLD measurements will have better SNR than HITS and an expanded spectral range that includes more of the total LBH emission. The forward model driving the optimal estimation routine includes the instrument line-shape and photoabsorption by $\mathrm{O}_{2}$.

Molecular oxygen $\left(\mathrm{O}_{2}\right)$ density profiles are derived using an algorithm is based on the Polar Ozone and Aerosol Measurement (POAM) solar occultation algorithm (Lumpe et al. 1997,2002 ) which have been used to retrieve $\mathrm{O}_{2}$ profiles from stellar occultations by SOLSTICE/SORCE (Lumpe et al. 2006). Retrievals for GOLD utilize 132-162 nm measurements to take advantage of the spectral dependence of the $\mathrm{O}_{2}$ absorption cross-section and maximize the altitude range covered (approximately 150-240 km). Since stars rise or set at approximately $3 \mathrm{~km} / \mathrm{sec}$, as observed from orbit, the 1 -second occultation cadence yields an effective vertical resolution of $10 \mathrm{~km}$ or better. The algorithm uses CPI's optimal estimation routines, which provide a complete error analysis.

The $135.6 \mathrm{~nm}$ nightglow emission is produced by the relaxation of oxygen atoms in the ${ }^{5} \mathrm{~S}$ state to the ground state, ${ }^{3} \mathrm{P}$ (DeMajistre et al. 2004; Meier 1991). There are two main sources of $\mathrm{O}\left({ }^{5} \mathrm{~S}\right)$ : radiative recombination of atomic oxygen ions $\left(\mathrm{O}^{+}\right)$with electrons $\left(\mathrm{e}^{-}\right)$ and mutual neutralization of $\mathrm{O}^{+}$and negative atomic oxygen ions $\left(\mathrm{O}^{-}\right)$, which are formed by attachment of electrons to neutral oxygen atoms (O) (DeMajistre et al. 2004). In addition, the radiance of the $135.6 \mathrm{~nm}$ nightglow is enhanced by resonance scattering by ambient oxygen atoms (Qin et al. 2015; Meier 1991). Modeling by Qin et al. (2015) demonstrates that mutual neutralization can contribute as much as $38 \%$ of the total $135.6 \mathrm{~nm}$ volume emission rate near the emission peak. However, the contribution to the column emission rate, which is what GOLD observers, is much smaller but non-negligible. Their modeling also demonstrates that the column emission rate may be enhanced by as much as $25 \%$ by resonant scattering. DeMajistre et al. (2004) along with many earlier authors (e.g., Chandra et al. 1975; Tinsley and Bittencourt 1975) have demonstrated that in the altitude region of peak electron density (and peak $135.6 \mathrm{~nm}$ emission) the positive ion concentration is nearly all $\mathrm{O}^{*}$ and that the total column emission is dominated by the contribution near the peak. Because both mutual neutralization and resonant scattering depend on the atomic oxygen profile, which GOLD does not measure at night, we have elected to neglect these processes in our algorithm, meaning that we derive an approximation to the nighttime peak electron density, $N_{\max }$, from the measured radiance at $135.6 \mathrm{~nm}$ by assuming a Chapman type electron density profile, which is what our algorithm does. The neglect of mutual neutralization and resonant scattering may result in an overestimation of $N_{\max }$ by as much as $25 \%$ but will usually be less.

Level 3 (L3) data products include averages and sums over longer time periods than those used for the L2 data products. These products will also include products produced with more modeling (and assumptions) than the L2 data products. For example, the L3 disk temperatures will include assumptions about the emission brightness and temperature profile along the line-of-sight while the L2 data product will assume an isothermal atmosphere.

\section{Conclusions}

The Global-scale Observations of the Limb and Disk (GOLD) mission will provide a new perspective on the global-scale response of the thermosphere-ionosphere (T-I) system to the forcing from above and below. As articulated in the most recent NRC Decadal Strategy 
for Solar and Space Physics, understanding the global-scale response of the thermosphereionosphere (T-I) system to these drivers is essential to advancing our physical understanding of coupling between the space environment and the Earth's atmosphere. Data from the GOLD imager, at geostationary orbit, enable the mission to follow the response of the T-I system as plasma and fluid processes compete to control its temperature, composition, and structure. The data can provide simultaneous images of two critical variablesthermospheric temperature and composition, near $160 \mathrm{~km}$ - on the dayside disk. At night, the mission will follow changes in the same geographic regions that were observed earlier in the day, enhancing our understanding of the low latitude ionosphere's evolution. Previous missions have successfully determined how the "climate" of the T-I system responds. The GOLD mission will take a long awaited step to understanding the coupling between the space environment and the Earth's atmosphere.

Acknowledgements Thanks to the managers, engineers, and technicians at the Laboratory for Atmospheric and Space Physics for their contributions to the design, fabrication, and testing of the GOLD instrument. Their expertise and efforts transformed the GOLD concept into an exceptionally capable scientific instrument. This work was supported by the National Aeronautics and Space Administration's Explorer Program through contract NNG19PQ28C to the University of Central Florida.

Open Access This article is distributed under the terms of the Creative Commons Attribution 4.0 International License (http://creativecommons.org/licenses/by/4.0/), which permits unrestricted use, distribution, and reproduction in any medium, provided you give appropriate credit to the original author(s) and the source, provide a link to the Creative Commons license, and indicate if changes were made.

\section{References}

J. Aarons, The role of ring current in the generation or inhibition of equatorial $\mathrm{F}$ layer irregularities during magnetic storms. Radio Sci. 4, 1131 (1991)

A.C. Aikin, A.E. Hedin, D.J. Kendig, S. Drake, Thermospheric molecular oxygen measurements using the ultraviolet spectrometer on the Solar Maximum Mission spacecraft. J. Geophys. Res. 98(A10), 17607 (1993)

A. Aksnes, R. Eastes, S. Budzien, K. Dymond, Neutral temperatures in the lower thermosphere from $\mathrm{N}_{2}$ Lyman-Birge-Hopfield (LBH) band profiles. Geophys. Res. Lett. 33, L15103 (2006). doi:10.1029/ 2006GL026255

A. Aksnes, R. Eastes, S. Budzien, K. Dymond, Dependence of neutral temperatures in the lower thermosphere on geomagnetic activity. J. Geophys. Res. 112, A06302 (2007). doi:10.1029/2006JA012214

S. Basu, Su. Basu, F.J. Rich, K.M. Groves, E. MacKenzie, C. Coker, Y. Sahai, P.R. Fagundes, F. BeckerGuedes, Response of the equatorial ionosphere at dusk to penetration electric fields during intense magnetic storms. J. Geophys. Res. 112(A8), A08308 (2007). doi:10.1029/2006JA012192

S.W. Bougher, K. Roeten, K. Olsen, P. Mahaffy, M. Benna, M. Elrod, S. Jain, N.M. Schneider, J. Deighan, E. Thiemann, F.G. Eparvier, A. Stiepen, B. Jakosky, The structure and variability of Mars dayside thermosphere from MAVEN NGIMS and IUVS measurements: seasonal and solar activity trends in scale heights and temperatures. J. Geophys. Res. 122, 1296-1313 (2017). doi:10.1002/2016JA023454

A.G. Burns, S.C. Solomon, W. Wang, T.L. Killeen, The ionospheric and thermospheric response to CMEs: challenges and successes. J. Atmos. Sol.-Terr. Phys. 69, 77 (2007). doi:10.1016/j.jastp.2006.06.010

A.G. Burns, S.C. Solomon, W. Wang, L. Qian, Y. Zhang, L.J. Paxton, X. Yue, J.P. Thayer, H.L. Liu, Explaining solar cycle effects on composition as it relates to the winter anomaly. J. Geophys. Res. 120, 5890 (2015). doi:10.1002/2015JA021220

A.G. Burns, W. Wang, S.C. Solomon, L. Qian, Energetics and composition in the thermosphere, in Modeling the Ionosphere-Thermosphere System (2014), pp. 39-48. doi:10.1002/9781118704417.ch4

S. Chandra, E. Reed, R. Meier, C. Opal, G. Hicks, Remote sensing of the ionospheric f layer by use of O I

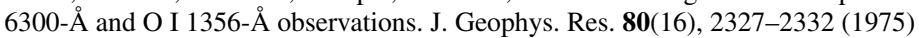

A.B. Christensen, L.J. Paxton, S. Avery, J. Craven, G. Crowley, D.C. Humm, H. Kil, R.R. Meier, C.-I. Meng, D. Morrison, B.S. Ogorzalek, P. Straus, D.J. Strickland, R.M. Swenson, R.L. Walterscheid, B. Wolven, Y. Zhang, Initial observations with the Global Ultraviolet Imager (GUVI) in the NASA TIMED satellite mission. J. Geophys. Res. 108(A12), 1451 (2003). doi:10.1029/2003JA009918 
M.V. Codrescu, T.J. Fuller-Rowell, V. Munteanu, C.F. Minter, G.H. Millward, Coupled thermosphere ionosphere plasmasphere electrodynamics model: CTIPE-mass spectrometer incoherent scatter temperature comparison. Space Weather 6, S09005 (2008). doi:10.1029/2007SW000364

J. Comberiate, L.J. Paxton, Global ultraviolet imager equatorial plasma bubble imaging and climatology, 2002-2007. J. Geophys. Res. 115, A04305 (2010). doi:10.1029/2009JA014707

G. Crowley, C. Hackert, R.R. Meier, D.J. Strickland, L.J. Paxton, X. Pi, A. Manucci, A. Christensen, D. Morrison, G. Bust, R.G. Roble, N. Curtis, G. Wene, Global thermosphereionosphere response to onset of November 20, 2003 magnetic storm. J. Geophys. Res. 111, A10S18 (2006). doi:10.1029/2005JA011518

R. DeMajistre, L.J. Paxton, D. Morrison, J.H. Yee, L.P. Goncharenko, A.B. Christensen, Retrievals of nighttime electron density from Thermosphere Ionosphere Mesosphere Energetics and Dynamics (TIMED) mission Global Ultraviolet Imager (GUVI) measurements. J. Geophys. Res. 100, A05305 (2004). doi:10.1029/2003JA010296

S.L. England, T.J. Immel, E. Sagawa, S.B. Henderson, M.E. Hagan, S.B. Mende, H.U. Frey, C.M. Swenson, L.J. Paxton, Effect of atmospheric tides on the morphology of the quiet time, postsunset equatorial ionospheric anomaly. J. Geophys. Res. 111, A10S19 (2006). doi:10.1029/2006JA011795

S.L. England, T.J. Immel, J.D. Huba, M.E. Hagan, A. Maute, R. DeMajistre, Modeling of multiple effects of atmospheric tides on the ionosphere: an examination of possible coupling mechanisms responsible for the longitudinal structure of the equatorial ionosphere. J. Geophys. Res. 115, A05308 (2010). doi:10.1029/2009JA014894

J.S. Evans, D.J. Strickland, R.E. Huffman, Satellite remote sensing of thermospheric O/N 2 and solar EUV 2. Data analysis. J. Geophys. Res. 100(A7), 12227-12233 (1995). doi:10.1029/95JA00574

J.S. Evans, D.J. Strickland, W.K. Woo, D.R. McMullin, S.P. Plunkett, R.A. Viereck, S.M. Hill, T.N. Woods, F.G. Eparvier, Early observations by the GOES-13 Solar Extreme Ultraviolet Sensor (EUVS). Sol. Phys. 262, 71-115 (2010). doi:10.1007/s11207-009-9491-X

J.M. Forbes, X. Zhang, S. Palo, J. Russell, C.J. Mertens, M. Mlynczak, Tidal variability in the ionospheric dynamo region. J. Geophys. Res. 113, A02310 (2008). doi:10.1029/2007JA012737

T.J. Fuller-Rowell, M.V. Codrescu, C.F. Minter, D. Strickland, Application of thermopsheric general circulation models for space weather operations. Adv. Space Res. 37, 401-408 (2006). doi:10.1016/ j.asr.2005.12.020

M. García-Comas, F. González-Galindo, B. Funke, A. Gardini, M. Jurado-Navarro, M. López-Puertas, W.E. Ward, MIPAS observations of longitudinal oscillations in the mesosphere and the lower thermosphere: Part 1. Climatology of odd-parity daily frequency modes. Atmos. Chem. Phys. Discuss. (2016). doi:10.5194/acp-2015-1065

M.E. Hagan, M.D. Burrage, J.M. Forbes, J. Hackney, W.J. Randel, X. Zhang, GSWM-98: results for migrating solar tides. J. Geophys. Res. 104(A4), 6813-6827 (1999). doi:10.1029/1998JA900125

J.D. Huba, G. Joyce, Global modeling of equatorial plasma bubbles. Geophys. Res. Lett. 37, L17104 (2010). doi:10.1029/2010GL044281

M.C. Kelley, J.J. Makela, L.J. Paxton, F. Kamalabadi, J.M. Comberiate, H. Kil, The first coordinated groundand space-based optical observations of equatorial plasma bubbles. Geophys. Res. Lett. 30(14), 1766 (2003). SSC 6-1. doi:10.1029/2003GL017301

H. Kil, S.Y. Su, L.J. Paxton, B.C. Wolven, Y. Zhang, D. Morrison, H.C. Yeh, Coincident equatorial bubble detection by TIMED/GUVI and ROCSAT-1. Geophys. Res. Lett. 31, L03809 (2004). doi:10.1029/2003GL018696

H. Kil, R.A. Heelis, L.J. Paxton, S.J. Oh, Formation of a plasma depletion shell in the equatorial ionosphere. J. Geophys. Res. 114, A11302 (2009). doi:10.1029/2009JA014369

J. Krall, J.D. Huba, C.R. Martinis, Three-dimensional modeling of equatorial Spread-F airglow enhancements. Geophys. Res. Lett. 36, L10103 (2009). doi:10.1029/2009GL038441

J. Lastovicka, Forcing of the ionosphere by waves from below. J. Atmos. Sol.-Terr. Phys. 68, 479-497 (2006). doi:10.1016/j.jastp.2005.01.018

B.M. Ledvina, J.J. Makela, First observations of SBAS/WAAS scintillations: using collocated scintillation measurements and all-sky images to study equatorial plasma bubbles. Geophys. Res. Lett. 32, 14 (2005). doi:10.1029/2004GL021954

D.Y. Lo, R.V. Yelle, N.M. Schneider, S.K. Jain, A.I.F. Stewart, S.L. England, J.I. Deighan, A. Stiepen, J.S. Evans, M.H. Stevens, M.S. Chan, M.M.J. Crismani, W.E. McClintock, J.T. Clarke, G.M. Holsclaw, F. Lefvre, B.M. Jakosky, Nonmigrating tides in the martian atmosphere as observed by maven iuvs. Geophys. Res. Lett. 42(21), 9057-9063 (2015). doi:10.1002/2015GL066268

J.D. Lumpe, R.M. Bevilacqua, K.W. Hoppel, S.S. Krigman, D.L. Kriebel, D.J. Debrestian, C.E. Randall, D.W. Rusch, C. Brogniez, R. Ramananahérisoa, E.P. Shettle, J.J. Olivero, J. Lenoble, P. Pruvost, POAM II retrieval algorithm and error analysis. J. Geophys. Res. 102(23), 593-614 (1997). doi:10.1029/2002JD002137 
J.D. Lumpe, R.M. Bevilacqua, K.W. Hoppel, C.E. Randall, POAM III retrieval algorithm and error analysis. J. Geophys. Res. 107(D21), 4575 (2002). doi:10.1029/2002JD002137

J.D. Lumpe, L. Floyd, M. Snow, T. Woods, Thermospheric remote sensing by occultation: comparison of SUSIM and SOLSTICE $\mathrm{O}_{2}$ measurements, in AGU Conference, San Francisco, CA, December 11-15 (2006)

J.D. Lumpe, L.E. Floyd, L.C. Herring, S.T. Gibson, B.R. Lewis, Measurements of thermospheric molecular oxygen from the solar ultraviolet spectral irradiance monitor. J. Geophys. Res. 112, D16308 (2007). doi:10.1029/2006JD008076

C. Martinis, J. Eccles, J. Baumgardner, J. Manzano, M. Mendillo, Latitude dependence of zonal plasma drifts obtained from dual-site airglow observations. J. Geophys. Res. 108(A3), 1129 (2003). doi:10.1019/2002JA009462

C. Martinis, M. Mendillo, J. Aarons, Toward a synthesis of equatorial spread F onset and suppression during geomagnetic storms. J. Geophys. Res. 110, A07306 (2005). doi:10.1029/2003JA010362

C. Martinis, M. Mendillo, ESF-related airglow depletions at Arecibo and conjugate observations. J. Geophys. Res. 112, A10310 (2007). doi:10.1029/2007JA012403

C. Martinis, J. Baumgardner, M. Mendillo, S.Y. Su, N. Aponte, Brightening of $630.0 \mathrm{~nm}$ equatorial Spread-F airglow depletions. J. Geophys. Res. 114, A06318 (2009). doi:10.1029/2008JA013931

C. Martinis, J. Baumgardner, M. Mendillo, J. Wroten, A. Coster, L. Paxton, The night when the auroral and equatorial ionospheres converged. J. Geophys. Res. 120, 8085-8095 (2015). doi:10.1002/ 2015JA021555

R.R. Meier, G. Crowley, D.J. Strickland, A.B. Christensen, L.J. Paxton, D. Morrison, C.L. Hackert, First look at the 20 November 2003 superstorm with TIMED/GUVI: comparisons with a thermospheric global circulation model. J. Geophys. Res. 110, A09S41 (2005). doi:10.1029/2004JA010990

R.R. Meier, J.M. Picone, D. Drob, J. Bishop, J.T. Emmert, J.L. Lean, A.W. Stephan, D.J. Strickland, A.B. Christensen, L.J. Paxton, D. Morrison, H. Kil, B. Wolven, T.N. Woods, G. Crowley, S.T. Gibson, Remote sensing of Earth's limb by TIMED/GUVI: retrieval of thermospheric composition and temperature. Earth Space Sci. 2, 1-37 (2015). doi:10.1002/2014EA000035

R.R. Meier, Ultraviolet spectroscopy and remote sensing of the upper atmosphere. Space Sci. Rev. 58(1), 1-185 (1991). doi:10.1007/BF01206000

G.H. Millward, I.C.F. Müller-Wodarg, A.D. Aylward, T.J. Fuller-Rowell, A.D. Richmond, R.J. Moffett, An investigation into the influence of tidal forcing on $\mathrm{F}$ region equatorial vertical ion drift using a global ionosphere-thermosphere model with coupled electrodynamics. J. Geophys. Res. 106, 24 (2001). doi:10.1029/2000JA000342

J. Oberheide, J.M. Forbes, Tidal propagation of deep tropical cloud signatures into the thermosphere from TIMED observations. Geophys. Res. Lett. 35, L04816 (2008). doi:10.1029/2007GL032397

S.H. Park, S.L. England, T.J. Immel, H.U. Frey, S.B. Mende, A method for determining the drift velocity of plasma depletions in the equatorial ionosphere using far-ultraviolet spacecraft observations. J. Geophys. Res. 112, A11314 (2007). doi:10.1029/2007ja012327

J.M. Picone, A.E. Hedin, D.P. Drob, A.C. Aikin, NRLMSISE-00 empirical model of the atmosphere: statistical comparisons and scientific issues. J. Geophys. Res. 107(A12), 1468 (2002). doi:10.1029/ 2002JA009430

G.W. Prölss, Density perturbations in the upper atmosphere caused by the dissipation of solar wind energy. Surv. Geophys. 32(2), 101-195 (2011). doi:10.1007/s10712-010-9104-0

J. Qin, J.J. Makela, F. Kamalabadi, R.R. Meier, Radiative transfer modeling of the OI $135.6 \mathrm{~nm}$ emission in the nighttime ionosphere. J. Geophys. Res. 120, 10116-10135 (2015). doi:10.1002/2015JA021687

A.D. Richmond, Y. Kamide, Mapping electrodynamic features of the high-latitude ionosphere from local observations: technique. J. Geophys. Res. 93, 5741-5759 (1988)

A.D. Richmond, E.C. Ridley, R.G. Roble, A thermosphere/ionosphere general circulation model with coupled electrodynamics. Geophys. Res. Lett. 19(6), 601-604 (1992)

O.H.W. Siegmund, J.V. Vallerga, J.B. McPhate, A.S. Tremsin, Next generation micro-channel plate detector technologies for UV astronomy. SPIE 5488, 789-800 (2004)

J.J. Sojka, J.B. Jensen, M. David, R.W. Schunk, T. Woods, F. Eparvier, M.P. Sulzer, S.A. Gonzalez, J.V. Eccles, Ionospheric model-observation comparisons: E layer at Arecibo Incorporation of SDO-EVE solar irradiances. J. Geophys. Res. 119, 3844-3856 (2014). doi:10.1002/2013JA019528

S. Solomon, L. Qian, Solar extreme-ultraviolet irradiance for general circulation models. J. Geophys. Res. 110, A10306 (2005). doi:10.1029/2005JA011160

S.C. Solomon, L. Qian, A.G. Burns, The anomalous ionosphere between solar cycles 23 and 24. J. Geophys. Res. 118, 6524 (2013). doi:10.1002/jgra.50561

D.J. Strickland, J.S. Evans, L.J. Paxton, Satellite remote sensing of thermospheric O/N2 and solar EUV: 1. Theory. J. Geophys. Res. 100(A7), 12217-12226 (1995). doi:10.1029/95JA00574 
D.J. Strickland, R.R. Meier, R.L. Walterscheid, A.B. Christensen, L.J. Paxton, D. Morrison, J.D. Craven, G. Crowley, Quiet-time seasonal behavior of the thermosphere seen in the far ultraviolet dayglow. J. Geophys. Res. 109, A01302 (2004a). doi:10.1029/2003JA010220

D.J. Strickland, J.L. Lean, R.R. Meier, A.B. Christensen, L.J. Paxton, D. Morrison, J.D. Craven, R.L. Walterscheid, D.L. Judge, D.R. McMullin, Solar EUV irradiance variability derived from terrestrial far ultraviolet dayglow observations. Geophys. Res. Lett. 31, L03801 (2004b). doi:10.1029/2003GL018415

D.J. Strickland, J.L. Lean, R.E. Daniell Jr., H.K. Knight, W.K. Woo, R.R. Meier, P. Straus, A.B. Christensen, T.N. Woods, F.G. Aparvier, D.R. McMullin, D. Morrison, L.J. Paxton, Constraining and validating Oct/Nov 2003 X-class EUV flare enhancements with observations of FUV dayglow and E-region electron densities. J. Geophys. Res. 112, A06313 (2007). doi:10.1029/2006JA012074

D.J. Strickland, J.S. Evans, J. Correira, Comment on "Long-term variation in the thermosphere: TIMED/GUVI observations" by Y. Zhang and L.J. Paxton. J. Geophys. Res. 117, A07302 (2012). doi:10.1029/2011JA017350

E.R. Talaat, R.S. Lieberman, Direct observations of nonmigrating diurnal tides in the equatorial thermosphere. Geophys. Res. Lett. 37, L04803 (2010). doi:10.1029/2009GL041845

B.A. Tinsley, J. Bittencourt, Determination of F region height and peak electron density at night using airglow emissions from atomic oxygen. J. Geophys. Res. 80(16), 2333-2337 (1975)

B.A. Tinsley, R.P. Rohrbaugh, W.B. Hanson, A.L. Broadfoot, Images of transequatorial F region bubbles in 630- and 777-nm emissions compared with satellite measurements. J. Geophys. Res. 102(A2), 20572078 (1997)

W. Wang, J. Lei, A. Burns, S. Solomon, M. Wiltberger, J. Xu, Y. Zhang, L. Paxton, A. Coster, Ionospheric response to the initial phase of geomagnetic storms: common features. J. Geophys. Res. 115, A7 (2010a). doi:10.1029/2009JA014461

W. Wang, J.H. Lei, A.G. Burns, S.C. Solomon, M. Wiltberger, J. Xu, Y. Zhang, L.J. Paxton, A. Coster, Ionospheric response to the initial phase of geomagnetic storms: 1. Common features. J. Geophys. Res. 115, A7 (2010b). doi:10.1029/2009JA014461

E. Weber, J. Buchau, R. Eather, S. Mende, North-South aligned equatorial airglow depletions. J. Geophys. Res. 83, 712 (1978)

T.N. Woods, F.G. Eparvier, S.M. Bailey, P.C. Chamberlain, J. Lean, G.J. Rottman, S.C. Solomon, W.K. Tobiska, D. Woodraska, The Solar EUV Experiment (SEE): mission overview and first results. J. Geophys. Res. 110, A01312 (2005). doi:10.1029/2004JA010765

T.N. Woods, P.C. Chamberlin, W.K. Peterson, R.R. Meier, P.G. Richards, D.J. Strickland, G. Lu, L. Qian, S.C. Solomon, B.A. Iijimaa, A.J. Mannucci, B.T. Tsurutani, XUV photometer system (XPS): improved solar irradiance algorithm using CHIANTI spectral models. Sol. Phys. 250, 235 (2008). doi:10.1007/s11207-008-9196-6

T.N. Woods, P.C. Chamberlin, J.W. Harder, R.A. Hock, M. Snow, F.G. Eparvier, J. Fontenla, W.E. McClintock, E.C. Richard, Solar Irradiance Reference Spectra (SIRS) for the 2008 Whole Heliosphere Interval (WHI). Geophys. Res. Lett. 36, L01101 (2009). doi:10.1029/2008GL036373

T.N. Woods, F.G. Eparvier, R. Hock, A.R. Jones, D. Woodraska, D. Judge, L. Didkovsky, J. Lean, J. Mariska, H. Warren, D. McMullin, P. Chamberlin, G. Berthiaume, S. Bailey, T. Fuller-Rowell, J. Sojka, W.K. Tobiska, R. Viereck, Extreme Ultraviolet Variability Experiment (EVE) on the Solar Dynamics Observatory (SDO): overview of science objectives, instrument design, data products, and model developments. Sol. Phys. 275, 115 (2012). doi:10.1007/s11207-009-9487-6

X.L. Zhang, J.M. Forbes, M.E. Hagan, J.M. Russell, S.E. Palo, C.J. Mertens, J. Christopher, M.G. Mlynczak, Monthly tidal temperatures 20-120 km from TIMED/SABER. J. Geophys. Res. 11(A10), A10S08 (2006). doi:10.1029/2005JA011504

Y. Zhang, L.J. Paxton, Long-term variation in the thermosphere: TIMED/GUVI observations. J. Geophys. Res. 116, A00H02 (2011). doi:10.1029/2010JA016337

Y. Zhang, L.J. Paxton, Reply to comment by D.J. Strickland et al. on "Long-term variation in the thermosphere: TIMED/GUVI observations". J. Geophys. Res. 117, A07304 (2012). doi:10.1029/ 2012JA017594 